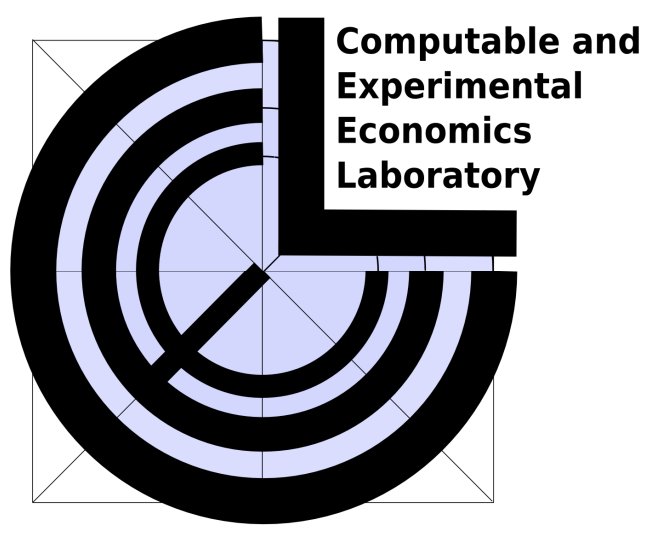

Giulio Bottazzi, Giovanna Devetag and Francesca Pancotto

Does Volatility matter? Expectations of price return and variability in an asset pricing experiment.

Computable and Experimental Economics Laboratory

Via Inama, 538100 Trento, Italy

http://www-ceel.economia.unitn.it tel. +39.461 .882246$ 


\title{
Does Volatility matter? Expectations of price return and variability in an asset pricing experiment*
}

\author{
Giulio Bottazzi $^{\text {a }} \quad$ Giovanna Devetag
March 30, 2009 \\ a LEM and CAFED, Scuola Superiore S. Anna, \\ Piazza Martiri della Liberta' 33, 56127 Pisa, Italy \\ b Dipartimento di Scienze Giuridiche ed Aziendali, \\ Universita' di Perugia, Via Pascoli, 2006123 Perugia, Italy
}

\footnotetext{
*Earlier versions of this paper have been presented at Universita' di Pisa, Universidad Carlos III Madrid, Scuola Superiore Sant'Anna in Pisa, Luiss Guido Carli Rome, HEC Management School of the University of Lige, Belgium. We thank all discussants for stimulating comments and helpful suggestions. We thank Ivan Soraperra, Marco Tecilla and the CEEL staff for assistance in the carrying out of the experiments, Andrea Brasili and Davide Fiaschi for useful comments and suggestions. The first author acknowledges financial support from the St.Anna School of Advanced Studies (grant n. E6003GB). The second author acknowledges support from MIUR (grant N. 2005139342002). The usual disclaimer applies.

${ }^{\dagger}$ Corresponding author. Tel.: +39-393-6019138; fax: +39-050-883343; e-mail: francesca.pancotto@me.com.
} 


\begin{abstract}
We present results of an experiment on expectation formation in an asset market. Participants to our experiment must provide forecasts of the stock future return to computerized utility-maximizing investors, and are rewarded according to how well their forecasts perform in the market. In the Baseline treatment participants must forecast the stock return one period ahead; in the Volatility treatment, we also elicit subjective confidence intervals of forecasts, which we take as a measure of perceived volatility. The realized asset price is derived from a Walrasian market equilibrium equation with non-linear feedback from individual forecasts. Our experimental markets exhibit high volatility, fat tails and other properties typical of real financial data. Eliciting confidence intervals for predictions has the effect of reducing price fluctuations and increasing subjects' coordination on a common prediction strategy.
\end{abstract}

JEL codes: C91,C92,D84,G12,G14

Keywords: Experimental economics, Expectations, Coordination, Volatility, Asset pricing 


\section{Introduction}

Understanding investors' expectations is crucial to model and predict the behavior of financial markets. Stock exchange professionals try to anticipate modifications in investor sentiment that are likely to impact on future price trends, and investors' beliefs are also central to economic theories of asset markets. Various researchers have tried to model investors' expectations by observing data obtained from 'real' markets, (e.g. Goetzmann and Massa, 2000; Grinblatt and Keloharju, 2001). However, the main problem with this method of studying beliefs is that expectations in the field are not directly observable, but can only be inferred (with varying degrees of error) from measurable variables such as price trends and trading volume. For this reason, other more direct means of collecting belief data have been attempted: among these are the use of surveys as in Turnovsky (1970), Frankel and Froot (1987), and Shiller (1990), and the design of controlled laboratory experiments. The last method is probably the most accurate to observe the dynamics of expectations, given the total control that the experimenter has over the parameters of the financial 'environment' in which investors operate. While the main focus of early experiments on asset markets was the impact of trading on deviation of prices from an asset fundamental value (with data on beliefs often collected as a "side-product"), more recent experiments focus on expectation formation in isolation from trading, or where no trading takes place (see, e.g., Hommes et al., 2005, 2008; Hey, 1994; Marimon and Sunder, 1993; Sonnemans et al., 2004). In these experiments subjects are usually asked to forecast future prices, either one period ahead, or several periods ahead. In some cases, the time series of prices is exogenously given, while in others it is endogenously generated by the participants' forecasting activity according to an expectations feedback mechanism. In the latter case, the relation between expectations and prices is usually a linear function, which makes both prediction of future prices and coordination of prediction strategies relatively easy.

In our experiment, we create an asset market with positive feedback from individual forecasts. The design is essentially adapted from Hommes et al. (2005): subjects are asked to forecast future returns of an asset, and these forecasts are used by artificial traders to buy or sell (optimal) amounts of the asset in every round. The pricing mechanism is obtained by assuming Constant Absolute Risk Aversion (CARA) behavior on the part of myopic (i.e., acting with one step time horizon) artificial speculators. Unlike previous experiments, we introduce a non-linear, positive feedback mechanism between forecasts and prices. In addition, in one of our treatments, we ask subjects to provide a confidence interval for their prediction, which we take as a measure of the perceived volatility of the 
corresponding return (and hence of the perceived risk of the investment). We use both forecasted return and forecasted volatility at time $t+1$ (we derive the latter from the confidence interval) to compute the price at time $t$; therefore subjects' forecasts on returns and confidence intervals have a direct impact on the price level. As a first step, we intend to investigate whether the presence of a non-linear feedback mechanism between forecasts and prices produces aggregate properties similar to those observed in real financial markets (in terms of, e.g., excess volatility and volatility clustering, fat tails, formation of bubbles and crashes) and a level of coordination in the prediction strategies of participants comparable to that observed in previous experiments that have employed linear expectations feedback functions (Hommes et al., 2005, 2008.) We introduce a non-linear feedback system, derived from the utility maximizing behaviour of our artificial traders, that more closely resembles the complexity of real financial markets. We then study the resulting aggregate properties of our experimental markets, focussing on both aggregate dynamics and interactions between these and the dynamics of individual expectations.

Secondly, we want to investigate if and how the elicitation of forecasts on volatility, in the form of a confidence interval, has an impact on the dynamics of prices and returns. Despite the obvious importance of perceived volatility (and hence perception of risk) for investment decisions in financial markets, to the best of our knowledge, no experiment so far has tested the role of volatility forecasts, alongside price forecasts, in influencing the dynamics of prices.

The remainder of the paper is organized as follows: in Section 2 we review the relevant literature; in Section 3 we describe the asset pricing model together with the experimental design and implementation. Section 4 reports results on aggregate market behavior while Section 5 discusses results on individual behavior. Section 5.2 discusses in detail data on predicted volatility. Finally, section 6 offers come concluding remarks.

\section{Related literature on expectations and volatility in financial markets}

Several contributions in economics and finance focus on the effect of behavioral factors on the stock pricing process. After the seminal contribution of Smith et al. (1988), several other studies tried to test the influence of trading on mispricing relative to fundamental values, and on the appearance of bubbles and crashes (see, for a review, Sunder (1995) and Camerer (1995) and the contributions in Markose et al. (2007). Common to many such experiments is the impossibility to separate the effects of different trading protocols from 
the effects of participants expectations ${ }^{1}$. Hence, with the purpose of isolating the role of expectations, some experiments elicited predictions of future prices from participants or observers of experimental markets, providing them with monetary incentives for accurate forecasts alone. Some of these experiments are not 'framed' in an asset pricing environment (e.g., Hey, 1994; Marimon and Sunder, 1993; Sonnemans et al., 2004, see also Camerer, 1995 for a review of early experiments on expectation formation). For example, Hey (1994) investigates expectation formation by asking participants to forecast the future values of a variable, knowing its past values, which are generated by a simple first order autoregressive process. The authors report a good average forecasting ability. Marimon and Sunder (1993) study pure expectations formation in an experimental version of the model of hyperinflation in Cagan (1956) based on an overlapping generations structure. They estimate simple forecasting rules and observe stable as well as very unstable price dynamics. Sonnemans et al. (2004) use a non linear cobweb model that generates unstable price dynamics for some parameter values. They design an experimental market with 6 subjects, in which no trade takes place, and in which the realized market price depends upon the aggregate demand and supply. The aggregate demand is given by the sum of participants' expectations at each round, while the supply schedule is non linear and monotonically increasing. Their results show rare convergence to the stable equilibrium while increasing amplitude of price fluctuations and the emergence of chaotic dynamics especially towards the end of the experiment.

In Hommes et al. (2005) the framework of forecasts elicitation is introduced by telling subjects that they are advisors to a pension fund that will make optimal investment decisions on the basis of their forecasts. The economy presents two investment options: a risk free asset and a risky asset, the latter paying uncertain dividends $y_{t}$, i.i.d. with constant mean. The fund chooses the relative share of the participant wealth that it wants to invest in the risky asset and, consequently, the complete portfolio composition. The task of the participants is to predict the price of the risky asset for the next period, given available information up to that point. The realized price at each time step is a weighted average of the participants expectations and of the fundamental price, where the weight is given by the share of "fundamentalists" computerized traders that enter the market when the distance between realized and fundamental price is above a specified threshold. The results show slow and monotonic convergence to the fundamental price, occurrence of bubbles and excess volatility. Moreover, subjects belonging to the same market are often able to coor-

\footnotetext{
${ }^{1}$ Many contributions have analyzed the role of different trading protocols over price dynamics, see for example Sunder (1995).
} 
dinate on a common prediction strategy. Hommes et al. (2008) replicates the same setting but removes the stabilizing, fundamentalist traders. Their data show ample bubbles that crash only when participants reach the upper price limit imposed by the software. The high degree of coordination in prediction strategies is confirmed in the new experiment. The authors explain their results with the positive, self-confirming nature of their feedback system combined with the existence of trend-confirming beliefs on the part of subjects: after experiencing a price increase, participants think that the price will increase further, and this expectations become self-fulfilling due to the positive feedback.

Haruvy et al. (2007) elicit traders' expectations of future price trajectories for a 15period lived asset, in a market structure well known to generate price bubbles and crashes. Their findings show that expectations are primarily adaptive; in addition, market peaks and downturns typically occur before traders expect them, even when these are experienced. Finally, in the presence of deviations from fundamental values, data on expectations can be profitably used to predict the direction of future price movements as well as the timing of market peaks.

Other experiments have tried to identify the microbehaviors responsible for a set of very well known stylized facts on the volatility of returns, namely, the non normality of excess returns, the presence of excess kurtosis and volatility clustering. Possible explanations of these phenomena abound in the theoretical literature (e.g., Dacorogna et al., 2001; Mandelbrot, 1936; Pagan, 1996). Within the empirical literature, some experimental studies have tried to find a relation between micro-behaviors of investors and stylized properties emerging in the series of returns.

In Plott and Sunder (1996), excess volatility and lack of autocorrelation in returns is observed in an asset pricing experimental market, although no explanations are offered for the phenomenon. Marimon et al. (1993) tries to give account of volatility in excess returns in a two-period lived overlapping generation model of agents trading a single consumption good and fiat money. Their results show that there is no creation of persistent volatility without exogenous shocks. On the other hand, there is persistence of price fluctuations after shocks, pointing at the role of expectations in the generation of persistence.

Kirchler and Huber (2007) introduce an asymmetric information structure of traders and continuous flows of new information in a double-auction trading market. The most informed trader, the insider, knows the current value as well as all past realized values of the dividend. The second best informed trader knows past realizations up to two periods back, the third up to three periods back, and so on. The dividend process is a random walk with drift, and, according to the authors, the structure intends to mimic real-world markets - in which information is first revealed only to insiders. A significant positive relationship 
between the degree of heterogeneity of fundamental information, and the emergence of stable decaying auto correlation of absolute returns is found in all treatments. The presence and persistence of volatility is explained by the heterogeneity of fundamental information: when new information is introduced in the market, prices start to fluctuate but at a decreasing level as traders learn from past prices and converge to the fundamental price. Similar dynamics are observed each time a new information shock is created.

Several previous studies have employed the elicitation of subjective confidence intervals in prediction tasks as a way to study the extent to which individuals exhibit overconfidence (e.g., Camerer 1995). Overconfidence emerges every time confidence intervals are of insufficient width (for example, when confidence intervals supposed to include the correct value with a probability of $99 \%$ do include it significantly less often). Overconfidence is considered responsible of a variety of 'irrational' behaviors in financial markets (Odean, 1998, 1999). While the experimental study of overconfidence mostly involves general knowledge questions or self-assessment of one's performance relative to some population average, some studies have measured overconfidence in the context of experimental asset markets. For example, Kirchler and Maciejovsky (2002) find that participants to a double auction in which confidence intervals for prices are elicited are not generally prone to overconfidence. In addition, they observe well-calibration as well as under- and overconfidence (Kirchler and Maciejovsky, 2002). Even if our primary goal is to study the impact of confidence intervals on price dynamics and how these intervals are influenced by market volatility, we will briefly discuss forecasters' overconfidence when describing our results.

\section{The Model}

Each participant to our experiment acts as advisor of a utility maximizing artificial trader (played by the software) who invests a certain amount of money in an asset market according to the participant's forecasts. Our market structure is similar to Hommes et al. (2005), although our subjects predict future returns instead of prices. We introduced this variant in order to be closer to what drives the portfolio allocation in 'real' financial markets, where the variable of interest is usually the rate of return over an investment rather than the price level of an asset. Furthermore, in our framework artificial traders act myopically with one-step time horizon, adapting their portfolios at each round. Hence, the price variation from round to round is the only variable of interest to them. The model is a simple asset market with a risky stock paying a constant dividend $D_{t}$ at each round and a risk-less bond with a constant return $R$. The diagram of the experimental setup is 
Figure 1: Experimental setting

Prevailing price

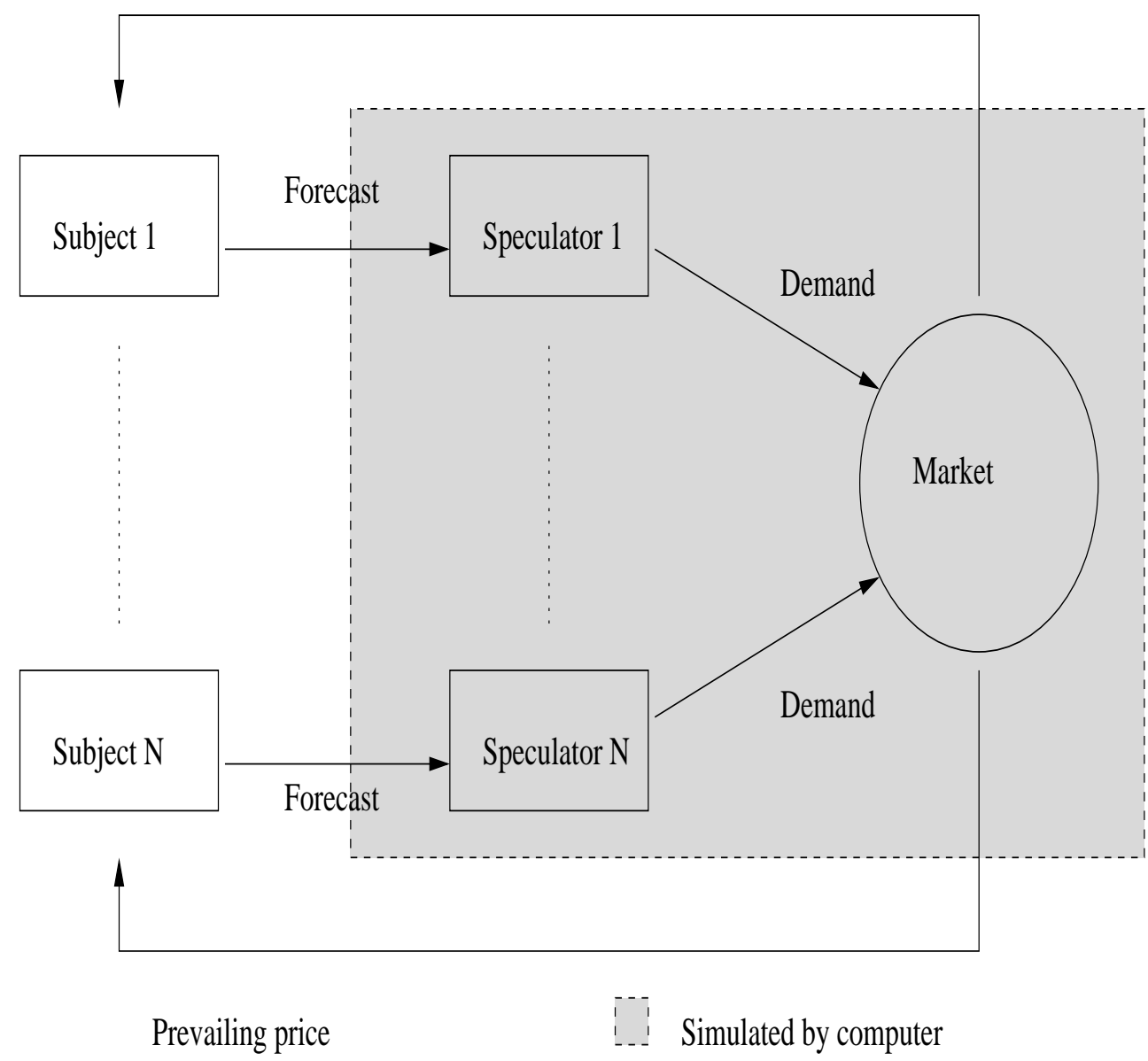

reported in Figure 1.

At each round of the experiment, participants are asked to provide predictions about the future value of the stock expected return (and volatility in one of the experimental treatments, see below). The artificial speculators use these forecasts to make optimal decisions over the demanded quantity of the risky asset in the current period. More precisely, their demand is obtained through the maximization of a CARA mean-variance utility function having future wealth as argument. Finally, the price is fixed by the software by aggregating the demands of the artificial speculators.

In the following we describe in detail the behavior of the artificial traders and the price fixing mechanism in order to derive the rules by which the participants' predictions generate the price at every time step. Then we move to discuss the mechanism through which subjects transmit their forecasts. 


\subsection{Artificial speculators behavior}

For simplicity, in this Section we drop any index relative to the artificial speculators since their investment behaviors are identical.

At time $t$ the artificial speculator intends to maximize the mean-variance utility $U_{t}$ of its wealth next period, $W_{t+1}$, given by

$$
U_{t}=\mathrm{E}\left[W_{t+1}\right]-\frac{\beta}{2} \mathrm{~V}\left[W_{t+1}\right],
$$

where $\mathrm{E}[$.$] and \mathrm{V}[$.$] stand for the expected value and variance of their argument, respec-$ tively, and where $\beta$ is a risk aversion parameter. The future wealth depends on the present wealth and on the investment decision. Let $x_{t}$ be the fraction of wealth the speculator wants to invest in the risky stock, so that the fraction $1-x_{t}$ is invested in the riskless security. If the prevailing price at time $t$ is $p_{t}$, the amount of shares bought reads $W_{t} x_{t} / p_{t}$, so that the future wealth is

$$
W_{t+1}=x_{t} W_{t} \frac{\left(p_{t+1}+D_{t}\right)}{p_{t}}+\left(1-x_{t}\right) W_{t}(1+R),
$$

where $R$ is the riskless return rate and $D_{t}$ the dividend paid per share of stock. The previous expression depends on both the present price $p_{t}$ and the next period price $p_{t+1}$. This dependence can be rewritten in terms of present price and price return

$$
W_{t+1}=x_{t} W_{t}\left(r_{t+1}+D_{t} / p_{t}-R\right)+W_{t}(1+R) .
$$

Substituting the previous expression in (1) and denoting by $\mathrm{E}_{t-1}$ and $\mathrm{V}_{t-1}$ the expectation and variance on future return ${ }^{2} r_{t+1}=p_{t+1} / p_{t}-1$ one obtains

$$
U_{t}=x_{t} W_{t}\left(\mathrm{E}_{t-1}-R+D_{t} / p_{t}\right)+W_{t}(1+R)-x_{t}^{2} \frac{\beta}{2} W_{t}^{2} \mathrm{~V}_{t-1} .
$$

Maximizing the speculator's utility with respect to $x_{t}$ gives the desired amount of the risky asset as a function of the notional price $P_{t}$. Hence, the demand function reads

$$
A_{t}\left(p_{t}\right)=\frac{\mathrm{E}_{t-1}-R+D_{t} / p_{t}}{\beta \mathrm{V}_{t-1} p_{t}} .
$$

Notice that the amount of stock demanded by the artificial speculator depends on exogenous experimental parameters, like the risk aversion parameter $\beta$ and the dividend process $D_{t}$, and on the input provided by the experimental subject, namely the forecasts $\mathrm{E}_{t-1}$ and $\mathrm{V}_{t-1}$.

\footnotetext{
${ }^{2}$ The subscript $t-1$ is to remind that these quantities are forecasted by experimental subjects based on information available at the beginning of round $t$, which includes the market history until round $t-1$.
} 


\subsection{Asset pricing}

The price of the stock is determined by simply equating aggregate supply and aggregate demand. Aggregate demand is defined as the sum of the demands for stock shares as in (5) over all the $N$ speculators trading in the market (in all our treatments $N=6$ ) while the supply $A_{\text {tot }}$, equivalent to the outstanding number of shares in the market, is assumed fixed. Hence, the prevailing price of the asset $p_{t}$ is the solution of

$$
\sum_{i=1}^{N} \frac{\mathrm{E}_{t-1, i}-R+D_{t} / p_{t}}{\beta_{i} V_{t-1, i} p_{t}^{*}}=A_{\mathrm{tot}} .
$$

The index $i$ runs over the different artificial speculators whose demands will be generally different due to differences in the risk aversion parameter and in subjects' predictions about future returns. Equation (6) reduces to a second order equation whose positive root is given by

$$
p_{t}=\frac{\overline{\mathrm{E}}_{t-1}}{2}+\sqrt{\left(\frac{\bar{E}_{t-1}}{2}\right)^{2}+\bar{D}_{t-1}}
$$

where

$$
\overline{\mathrm{E}}_{t-1}=\sum_{i=1}^{N} \frac{\mathrm{E}_{t-1, i}-R}{A_{\mathrm{tot}} \beta_{i} \mathrm{~V}_{t-1, i}} \quad \text { and } \quad \bar{D}_{t-1}=\sum_{i=1}^{N} \frac{D_{t}}{A_{\mathrm{tot}} \beta_{i} V_{t-1, i}}
$$

are the average expected excess return and the average expected dividend, both weighted with respect to the inverse perceived risk.

Equation 7 provides a positive price even if the average expected excess return $\bar{E}_{t-1}$ is negative. We can define the pricing equation as a positive expectations feedback system, in the spirit of Heemeijer et al. (2006). ${ }^{3}$ In fact, although forecasts are on returns, it is nonetheless true that a higher average forecasted return yields a higher realized market price. On the other hand, the opposite is true for the forecasted variance. The higher the value of forecasted variance, ceteris paribus, the lower the realized market price. The above pricing equation has been obtained without considering any budget constraint for the traders.

Once the price at time $t$ is determined, the trader's demand of the risky asset, $A_{t-1, i}$, is fixed and using the past price $p_{t-1}$, one can determine the realized payoff of each trader (and participant) per period, namely

$$
\pi_{t, i}=A_{t-1, i}\left(p_{t}+D-p_{t-1}(1+R)\right)
$$

\footnotetext{
${ }^{3}$ The dynamic properties of this pricing equation are extensively studied in Bottazzi (2002).
} 
Table 1: Experimental parameters

\begin{tabular}{cc} 
Parameter & Value \\
\hline$\beta$ & 1 \\
$D$ & 3 \\
$R$ & 0.05 \\
$A_{\text {tot }}$ & 100 \\
\hline
\end{tabular}

\subsection{The experimental design}

Subjects were told that they would participate in a financial market composed of six participants, in which their task was to provide forecasts for a total of 52 periods. Their earnings would depend on the performance achieved according to Eq. (9).

We run two treatments, denoted Baseline and Volatility Treatments respectively. In both treatments the interest rate $R$ was set equal to $5 \%$, the number of outstanding shares $A_{\text {tot }}$ was equal to 100 and the risk aversion parameter of the artificial speculators equal to 1 , i.e. $\beta_{i}=1, \forall i$. Moreover, given that we are only interested in the speculative returns obtainable from price changes, we considered a fixed value for the dividend $D_{t}$ : hence, $D_{t}=D \forall t$, with $D=3$ ECUs (experimental currency units). In addition, we consider the risky asset as infinitely lived, given that our investors act with one-step time horizon. In this way the fundamental value of the stock corresponds to the present value of the discounted future dividends, is equal to $p^{f}=D / R=60$. See Table 1 for a summary of the relevant parameters.

In the Baseline Treatment (henceforth, BT) each participant is asked to provide, at the beginning of time $t$ and with the information available up to time $t-1$, the value $E_{t-1, i}$ of the return that he/she expects the asset will exhibit in period $t+1$. The reason why a predictor should care about the price two periods ahead is justified intuitively by the fact that the asset has to be bought at period $t$ and then sold at $t+1$ to make a profit. In BT forecasted variance is fixed at the value $V_{t-1, i}=\bar{V}=0.0005$. In the Volatility Treatment (VT henceforth), each participant is asked to provide a forecast of the asset return as in BT, plus a confidence interval of his/her prediction. In practice, we told our subjects that the range should be such to include the future return with a probability of $95 \%$, equivalent to the 2 standard deviation range of a normal distribution. The forecaster provides a single number $v_{t, i}$ that is transformed into a confidence range using the rule: $\left(-v_{t, i}, v_{t, i}\right)$ for any $i$. The prices in each round are then determined by Eq. (7) using the estimated values of 
predicted returns and variances, where the value for the variance $V_{i}$ is obtained from $v_{i}$, by the formula:

$$
V_{i}=\frac{\left(v_{i}\right)^{2}}{4}
$$

The expected returns could be either positive or negative, and could vary between -50000 and +50000 . The values for the confidence range could be only positive and were expressed in percentage (i.e., a value of 3 was interpreted as a confidence interval of $\pm 3 \%$ ). They could vary from 1 to 100. At the end of round $t$, each participant received information about: the realized price $p_{t}$, the new realized return $r_{t}$ and the realized profit from the previous round $\pi_{t}$. Note that our payoff generating function differs from the quadratic scoring rule ${ }^{4}$ in Hommes et al. (2005) which never generates negative payoffs. Our per-round profit (and cumulative profit as a consequence) can assume also negative values, according to what may occur to "real" investments in financial markets ${ }^{5}$. We are aware of the fact that our subjects may react to losses differently from how they react to corresponding gains (see Kahneman and Tversky, 1979). A further difference with the framework in Hommes et al. (2005) and Hommes et al. (2008) is the fact that our subjects were informed of the endogenous nature of realized prices and returns, and knew the relevant equations that determined the price in each round on the basis of their forecasts. This information was made common knowledge. We introduced this change because we intended to give subjects the best chance to coordinate on a common prediction strategy.

\subsection{Main hypotheses}

We formulate three main hypotheses as a guide to our experimental design - they will serve us to analyze the results. The first hypothesis concerns the aggregate behavior of our experimental markets in terms of the time series of prices. Previous experiments that have used a similar framework (e.g. Hommes et al., 2005, 2008) have found smooth bubbles that crashed as the market end approached, or ample fluctuations around the fundamental value that decreased in magnitude over time. A further, robust finding, was the ability of subjects belonging to the same market to coordinate on a common prediction strategy, despite the absence of communication. An aspect common to all these previous experiments is the use of a linear positive feedback mechanism, by which the price in each round resulted from a simple (sometimes weighted) average of participants' expectations in the previous round. In our framework we introduce a non-linear component in the feedback mechanism

\footnotetext{
${ }^{4}$ The precise formulation is $e_{h, t}=\max \left\{1300-(1300 / 49)\left(p_{t}-p_{h, t}^{e}\right)^{2}, 0\right\}$

${ }^{5}$ The possibility to realize a loss in the experimental currency units did not, however, translate into a real loss as far as final payment in euros is concerned.
} 
in both our treatments. We hypothesize that the increased complexity of our framework may impact on the ability of subjects to coordinate; as a consequence, we expect to observe a higher level of volatility in the time series of prices with respect to previous experiments. Therefore, we formulate the following

Hypothesis 1 Our market setting will show higher volatility of prices with respect to previous experimental markets of the same type

The second hypothesis concerns differences between our two treatments. In the Volatility Treatment we ask subjects to explicit their degree of confidence in the accuracy of their forecast by providing a confidence interval. Subjects know that the larger the interval they provide, the lower the demand for assets of the computerized trader, meaning that larger intervals imply more "cautious" positions in the market. Besides, the elicitation of volatility per se may determine a higher awareness of the risk implicit in the investment decision. These factors should have an effect on returns and on the degree of coordination in subjects' predictions. Hence, we formulate our second hypothesis:

Hypothesis 2 In the Volatility treatment, we should observe lower volatility of returns compared to the Baseline treatment. As a consequence, in the Volatility treatment, we should observe a higher degree of coordination in participants' predictions.

Finally, our third hypothesis concerns the elicitation of confidence intervals. We formulate

Hypothesis 3 Confidence intervals increase with the volatility of realized returns and prices in the market, meaning that participants understand increasing market risk and behave consequently

\subsection{The experiment implementation}

The experiment was entirely computerized and took place in one of the computer rooms of the Computable and Experimental Economics Lab of the University of Trento. A total of eight experimental sessions were conducted, with twelve players participating in each session $^{6}$, for a total of 90 subjects. Each market was composed of six participants, therefore we collected 7 independent observations for BT, and 8 independent observations for

\footnotetext{
${ }^{6}$ An exception was session four of the Baseline Treatment, where only six subjects participated due to some of the other subjects not showing up in time.
} 
VT. Subjects were randomly assigned to the different treatments. They were mostly undergraduate students in economics and had never participated in experiments of this type before. Before the experiment began, subjects received paper copies of the instructions which were read aloud by the experimenter to make sure that the rules of the market were common information among participants. ${ }^{7}$ In addition, a handout with a summary of the market rules together with the specification of the relevant parameters was also given to every subject to keep during the experiment. Subjects were in the same room but were prevented from looking at each other's computer screens by wooden separators. Subjects were also informed that there was no dependence between the investment choices made in different rounds.

Their final earnings would be determined by the sum of their earnings in every round, expressed in ECU, and converted into euros as follows: the participant within the market that had achieved the highest cumulative payoff would receive an amount of $25 €$, while the participant with the minimum cumulative payoff would receive an amount of $5 €$. All other participants in the market would earn a payoff proportional to the maximum achieved. Subjects were informed of the payoff assignment rule but did not have any information throughout the experiment about the earnings of other participants, therefore such payoff assignment rule gave them the highest incentive to maximize their earnings. Finally, although subjects knew that the market would be composed of six participants, they did not know the identity of the other five participants in the same market.

At the beginning of each round subjects entered their forecasts by typing the numbers in the appropriate windows and by pressing 'enter'. Fig. 2 reports a sample of the computer interface.

There were no time constraints imposed. The bottom left corner of the screen reported the values of the risk-free rate and of the dividend in each period, and the central part of the screen contained a table and a graph: the table had five columns reporting the round number, the realized price in that round, the realized return, the expected return (the subject's prediction), and the subject's cumulated payoff. Besides, the graph visualized two lines reporting the values of price and return over time. Hence, subjects had full feedback regarding the values of the price and return (both numerically and visually), and could also see the difference between their forecast and the realized value of the return, which were reported in the table. Subjects never had any feedback regarding other participants' forecasts and their realized earnings. Sessions lasted one hour and a half, on average.

\footnotetext{
${ }^{7}$ A complete English translation of the instructions is available in Appendix 7.
} 
Figure 2: Computer Interface of the Experiment Software.

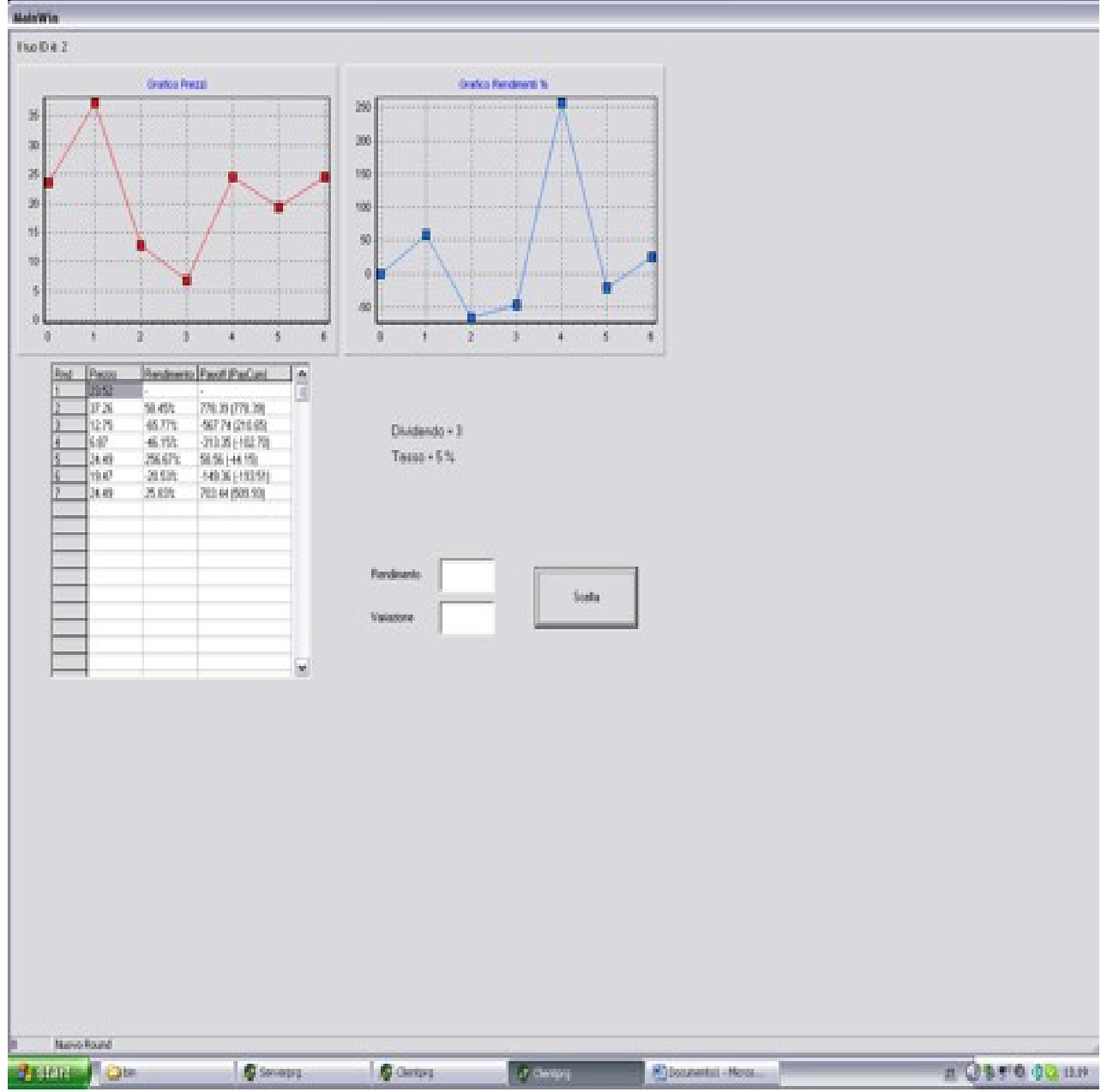

\section{Results: Aggregate Market Behavior}

Before discussing our results, it is useful to recall some typical features of "real" financial markets, as these have been identified in the empirical literature: first, returns in real markets typically show high volatility. ${ }^{8}$ Furthermore, autocorrelation in the series of returns in levels is absent, but a strong decaying autocorrelation in absolute values is observed. Real data also typically show excess kurtosis (fat tails) (Dacorogna et al., 2001) and high skewness (Mandelbrot, 1936), pointing at the presence on non-Gaussian behaviors of returns distributions. Returns in our markets are computed discretely as $r_{t+1}=\left(p_{t+1}-p_{t}\right) / p_{t}$ where $r_{t+1}$ is the realized return at $t+1, p_{t}$ is the corresponding price at time $t$.

Figure 3 reports the $\log$ series of prices over time for the Baseline treatment, and

\footnotetext{
${ }^{8}$ See Bollerslev et al., 1994; Ghysels et al., 1996.
} 
Figure 3: Log Prices of the markets of the Baseline Treatment
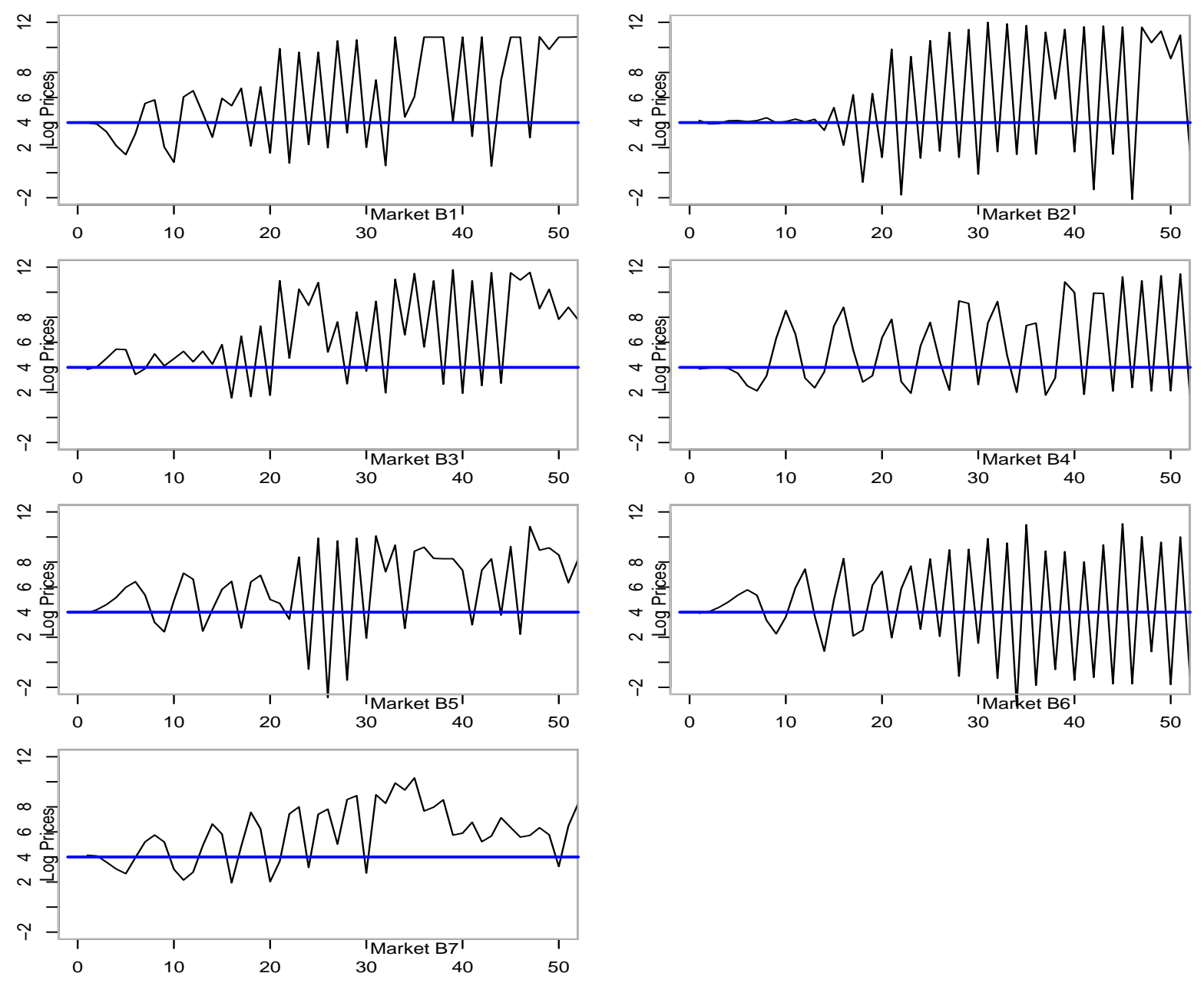

Figure 4 reports the same information for the Volatility treatment. The straight line reports the asset fundamental value. In general the time series display high volatility in realized prices, with no smooth convergence to the fundamental price over time.

In the Baseline Treatment, some markets show regular period-two oscillations of increasing amplitude (Market B1, B2, B3, B6) and in some instances the onset of short term bubbles toward the end (Market B2, B3, B5 and B7). No convergence to the fundamental price is ever observed. In the Volatility Treatment, we observe more stable price dynamics, with some markets showing very small oscillations around the fundamental value (Market V2 and V3) or stable values above it (Market V1). In some other cases the price is stable up to a certain point, after which oscillations increase substantially (V5, V7 and V8). In Market V4 a positive price trend is observed, with frequent bubbles of short duration. Overall, 
Figure 4: Log Prices of the markets of the Volatility Treatment
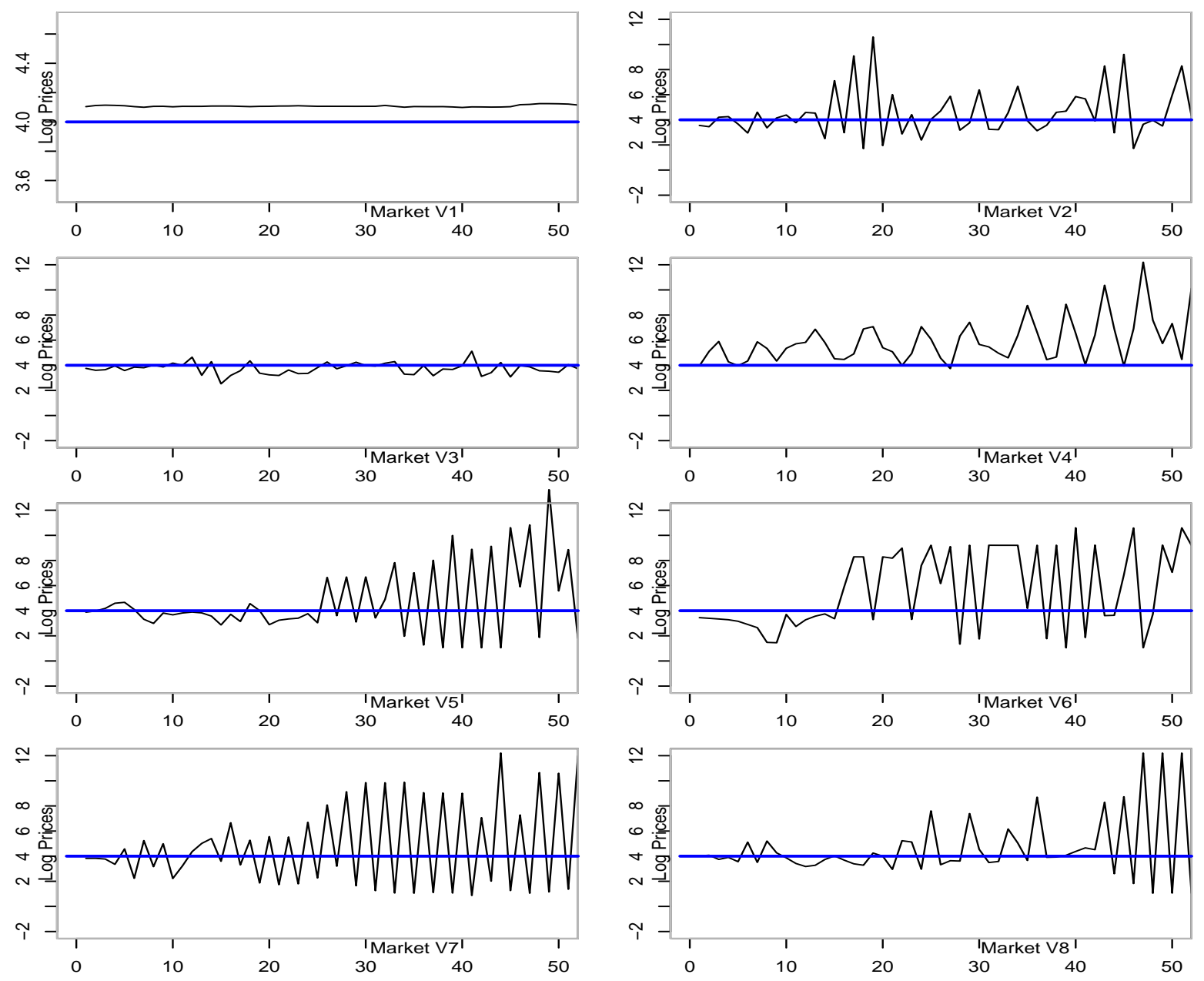

hence, we do not observe the smooth bubbles that emerged in previous experiments with a linear feedback system. In addition, volatility is on average very high.

Therefore, our Hypothesis 1 is supported by the data: With respect to previous experimental asset markets that employed positive feedback from individual forecasts, our markets show a higher degree of price volatility.

Table 2 reports some descriptive statistics of our experimental markets, divided by treatment. Together with the average price and return levels, we report values for the return kurtosis to check for the existence of fat tails: if kurtosis is greater than 3, the distribution is leptokurtic, with more 'acute' peaks and higher probability of extreme values than a normal distribution. We also calculate the skewness of retuns distributions, which measures the extent to which the distribution is symmetric around the mean, compared to 
Table 2: Descriptive statistics, divided by market and treatment. Standard deviation is calculated on successive time windows of ten periods. Std. dev., kurtosis and skewness refer to returns.

Baseline Treatment

\begin{tabular}{rrrrrrr}
\hline \hline Mkts & Avg. Price & Avg. Ret. & Std. Deviation & Kurtosis & Skewness & N. obs \\
\hline B1 & 14564 & 1111.46 & 2838 & 38.62 & 5.85 & 51 \\
B2 & 28268.4 & 35385.62 & 76078 & 30.42 & 5.19 & 51 \\
B3 & 18878.6 & 1014.0 & 2079 & 6.99 & 2.42 & 51 \\
B4 & 9137.4 & 829.82 & 1145 & 12.25 & 3.22 & 51 \\
B5 & 4371.5 & 7759.5 & 17338 & 39.80 & 6.04 & 51 \\
B6 & 5259.5 & 53801.97 & 146388 & 45.28 & 6.54 & 51 \\
B7 & 2301.1 & 14.61 & 35.44 & 46.10 & 6.62 & 51 \\
Average & 11825.8 & 14273.8 & 35129 & 31.35 & 5.12 & \\
\hline \hline & & & & & \\
Volatility Treatment & & & & & \\
\hline \hline & & & & & \\
Mkts & Avg. Price & Avg. Ret. & Std. Deviation & Kurtosis & Skewness & N. obs \\
\hline V1 & 60.82 & $2.21 \mathrm{e}-04$ & 0.003 & 5.96 & 1.02 & 51 \\
V2 & 1404.7 & 166.41 & 487.6 & 48.15 & 6.83 & 51 \\
V3 & 46.85 & 0.195 & 0.632 & 3.85 & 0.904 & 51 \\
V4 & 5587.21 & 13.21 & 18.18 & 23.75 & 4.58 & 51 \\
V5 & 18948.8 & 3083.7 & 8538 & 47.48 & 6.76 & 51 \\
V6 & 5147.2 & 438.64 & 1172 & 42.52 & 6.25 & 51 \\
V7 & 10463.35 & 2372.4 & 2606 & 19.6 & 4.01 & 51 \\
V8 & 11975.09 & 3377.5 & 5892 & 19.38 & 4.21 & 51 \\
Average & 6704.25 & 1181.50 & 2339 & 26.33 & 4.32 & \\
\hline \hline & & & & & \\
\hline
\end{tabular}

the normal distribution. A positive skew indicates a distribution favoring the right tail.

Table 2 confirms the results of the graphical analysis: in the Baseline treatment, some markets are characterized by strong volatility, as expressed by the standard deviation of returns, in particular Markets B2, B5, B6, B8, and show evidence of fat tails and skewness. On the contrary, Markets B3, B4 and in particular B7 are much less volatile. In addition, all markets are characterized by non normality, fat tails and asymmetry, although with some differences. 
In the Volatility Treatment, Market V3 presents features typical of a normal distribution, with a value of kurtosis close to three and skewness around zero. Standard deviation is very low and the average price is close to the fundamental value. Market V3 is noteworthy for two reasons: first, it allows us to state that the asset pricing equations of our model are not bound to produce complex behaviors, but that such behavior, if and when it emerges, is the result of participants' expectations. In addition, the dynamics observed in market V3 emerge when we elicit confidence intervals: the outcome of this market is consistent with the fact that, in general, a lower volatility is observed in the Volatility treatment with respect to the Baseline treatment, in line with our Hypothesis 2. This is also evident in Market V1, where participants trade at a value slightly below the fundamental price, with almost no variation throughout. Complex dynamics, however, arise in this treatment as well: non-gaussian behaviors, high standard deviations, excess kurtosis and skewness characterize some of the markets as for example market 5, the most 'chaotic' market.

Looking at Table 2, we can observe that in most cases the average realized price is highly above the fundamental value of 60 , with two exceptions, both in the Volatility treatment. In both treatments the realized price is significantly different from the fundamental value according to a T-test $(p=0.016$ for the Baseline treatment and $p=0.026$ for the Volatility treatment). The difference between the two treatments is not, however, statistically significant according to a Mann-Whitney $\mathrm{U}$ test $(p=0.335$, two-tailed). Looking at average returns, we can observe that the values of realized returns are always positive on average, and, in the Baseline treatment one order of magnitude higher than in the Volatility treatment (the difference is statistically significant according to a MannWhitney $\mathrm{U}$ test, $p=0.056$, one-tailed). In other words, the observed return values in the Volatility treatment are more similar to returns in real financial markets. Likewise, the observed value of the standard deviation differs remarkably in the two treatments, with much higher values in the Baseline treatment. The difference is statistically significant ( $p=0.056$, Mann-Whitney U test, one-tailed). Hence, the first part of our second hypothesis is confirmed: In the Volatility treatment, markets show a lower volatility of returns compared to the Baseline treatment.

We conclude this section by observing that our markets show remarkable volatility of realized prices over time, high frequency of period-two cycles, and several characteristics of realized returns that resemble features commonly observed in real financial markets (e.g., bouncing effect, non-normality, fat tails and skewness). Our two treatments, moreover, differ with respect to the volatility of both prices and returns with a relative higher abundance of stable markets in the Volatility treatment. 


\section{Individual Behaviors and Market Dynamics}

In this section we analyze individual prediction strategies, and the degree of coordination among strategies of subjects belonging to the same market. We also want to test the existence of relations between properties of the series of prices and returns, and the characteristics of individual forecasts.

\subsection{Coordination}

Table 3 reports the average predicted return of our experimental subjects, separately for each market and averaged over the 52 rounds of the experiment. The top part of the table reports values for the Baseline treatment and the bottom part values for the Volatility treatment. The last two columns report the market average and standard deviation of individual predicted returns, respectively.

On average, forecasted returns in the markets belonging to the Baseline treatment are twice as high as those in the markets of the Volatility treatment (the difference is weakly significant: Mann-Whitney U test, $p=0.06$ ). This is consistent with the much higher values of the realized returns observed in the Baseline treatment. The standard deviation of forecasted returns (last column of Table 3) is likewise higher in the Baseline than in the Volatility treatment. We use the standard deviation as a proxy for the level of consensus about the future return among participants to the same market, and, consequently, for the degree of coordination achieved. The lower the standard deviation, the higher the consensus within the same market. The difference between the standard deviations of the two treatments is significant at the $10 \%$ level (Mann-Whitney $\mathrm{U}$ test, $p=0.09$, onetailed). This finding suggests that there was a higher degree of consensus in the predictions of subjects participating in the Volatility treatment.

Figure 5 reports the standard deviation of predicted returns over time, averaged across markets and separately for the two treatments.

Each data point is the standard deviation of individual predictions within the same market at each time step, averaged across markets in the same treatment and over successive time windows of 5 steps. Two observations are noteworthy: first, the standard deviation increases substantially over time in both treatments, revealing an increasing dispersion of individual predictions which suggests, perhaps, an increasing difficulty at coordinating. Secondly, as confirmed by data in Table 3, the standard deviation in the Volatility treatment is always lower than the corresponding value in the Baseline treatment. Hence, asking subjects to provide a confidence interval has the effect of making individual predictions 
Table 3: Average Predicted Returns and Average Absolute Deviation from the Mean of predicted Returns.

Baseline Treatment

\begin{tabular}{lcccccccl}
\hline \hline \multicolumn{1}{l}{ Average Predicted Returns } \\
\hline Mkts & Ag. 1 & Ag. 2 & Ag. 3 & Ag. 4 & Ag. 5 & Ag. 6 & Avg. & \\
\hline B1 & 0.0038 & 123.2 & -0.14 & 20.87 & 0.13 & 0.53 & 24.1 & 33.01 \\
B2 & 21.30 & 46.32 & 66.91 & 100 & 16.72 & 23.21 & 45.8 & 25.33 \\
B3 & -0.16 & 20.76 & 51.35 & 0.48 & 56.37 & 59.69 & 31.45 & 24.38 \\
B4 & 30.78 & 11.60 & 48.45 & 0.04 & 0.01 & 0.02 & 15.15 & 16.31 \\
B5 & 18 & -0.016 & 0.16 & 16.13 & 1.50 & 0.07 & 6 & 7.4 \\
B6 & -0.22 & 5.10 & -1.6 & 11.59 & -0.29 & 12.74 & 4.55 & 5.25 \\
B7 & 15.83 & 0.69 & 6.10 & -3.72 & 1.28 & 2.77 & 3.83 & 4.76 \\
Average & & & & & & 18.68 & 16.63 \\
\hline \hline
\end{tabular}

Volatility Treatment

\begin{tabular}{lcccccccl}
\hline \hline \multicolumn{1}{l}{ Average Predicted Returns } \\
\hline Mkts & Ag. 1 & Ag. 2 & Ag. 3 & Ag. 4 & Ag. 5 & Ag. 6 & Avg. & \\
\hline V1 & -0.02 & 0.02 & 0.04 & 0.00 & 0.30 & 0.11 & 0.08 & 0.09 \\
V2 & 0.53 & 0.51 & 0.06 & 0.05 & 15.46 & 0.07 & 2.78 & 4.23 \\
V3 & 0.15 & 0.39 & 0.17 & 0.47 & 0.16 & 0.07 & 0.24 & 0.13 \\
V4 & 0.02 & 20.48 & 0.29 & -0.003 & 0.21 & 0.44 & 3.58 & 5.63 \\
V5 & 10.41 & 9.18 & 0.83 & 5.10 & 30.43 & 0.06 & 9.34 & 7.4 \\
V6 & 0.07 & 36.08 & 8.14 & 17.35 & 0.37 & 2.70 & 10.8 & 10.62 \\
V7 & 0.04 & 32.96 & 76.15 & 2.10 & 42.83 & 99.29 & 42.23 & 30.53 \\
V8 & -0.33 & 32.35 & 0.02 & -1.08 & 0.01 & 0.35 & 5.22 & 9.04 \\
Average & & & & & & 9.27 & 8.46 \\
\hline \hline
\end{tabular}

less dispersed and increasing their degree of coordination. This in turn may depend on the fact that realized prices and returns in the Volatility treatment are more easily predictable (this is evidently so in the most stable markets such as market V1 and V3). More chaotic dynamics, on the contrary, trigger lack of predictability. At the same time, the it may 
Figure 5: Standard Deviation of predicted returns over time for the two treatments. Each data point is the standard deviation of individual predictions within the same market at each time step, averaged across markets and successive time windows of 5 periods.

\section{Standard Deviation of Predicted returns}

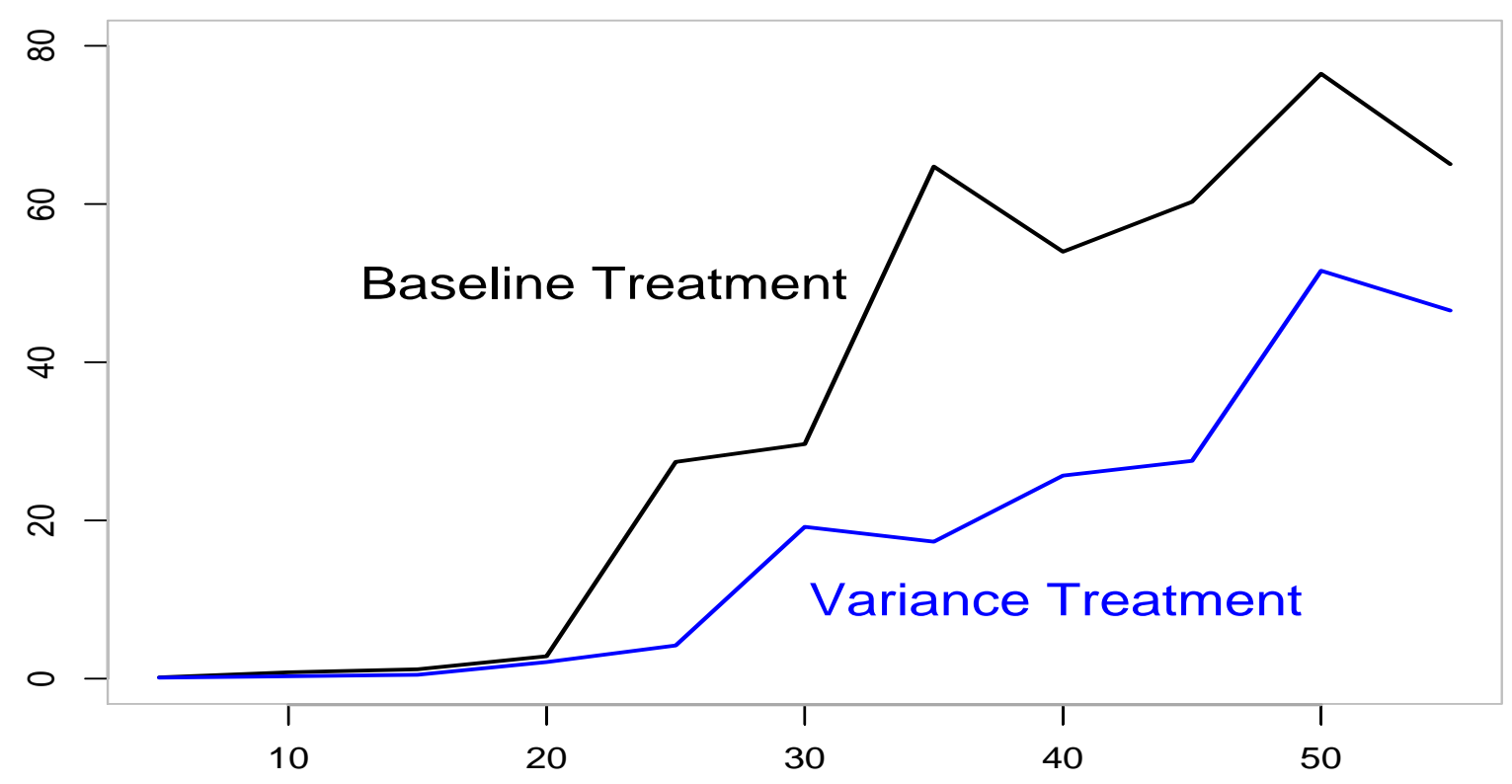

be the sheer elicitation of confidence intervals to "tame" the inherently complex dynamics induced by the non-linear feedback mechanism.

Therefore, the second part of Hypothesis 2 is confirmed: In the Volatility treatment, there is a higher degree of coordination in subjects' predictions compared to the Baseline treatment.

Figure 6 reports the same data, disaggregated for every market, separately for the Baseline and the Volatility treatment.

Data in the Baseline treatment show a high variability across markets, notwithstanding an increased dispersion occurring in all markets from period 20 onward. The dispersion 
Figure 6: Standard Deviation of predicted returns per market. Each data point is the standard deviation of individual predictions within the same market at each time step, averaged over successive time windows of 5 periods.
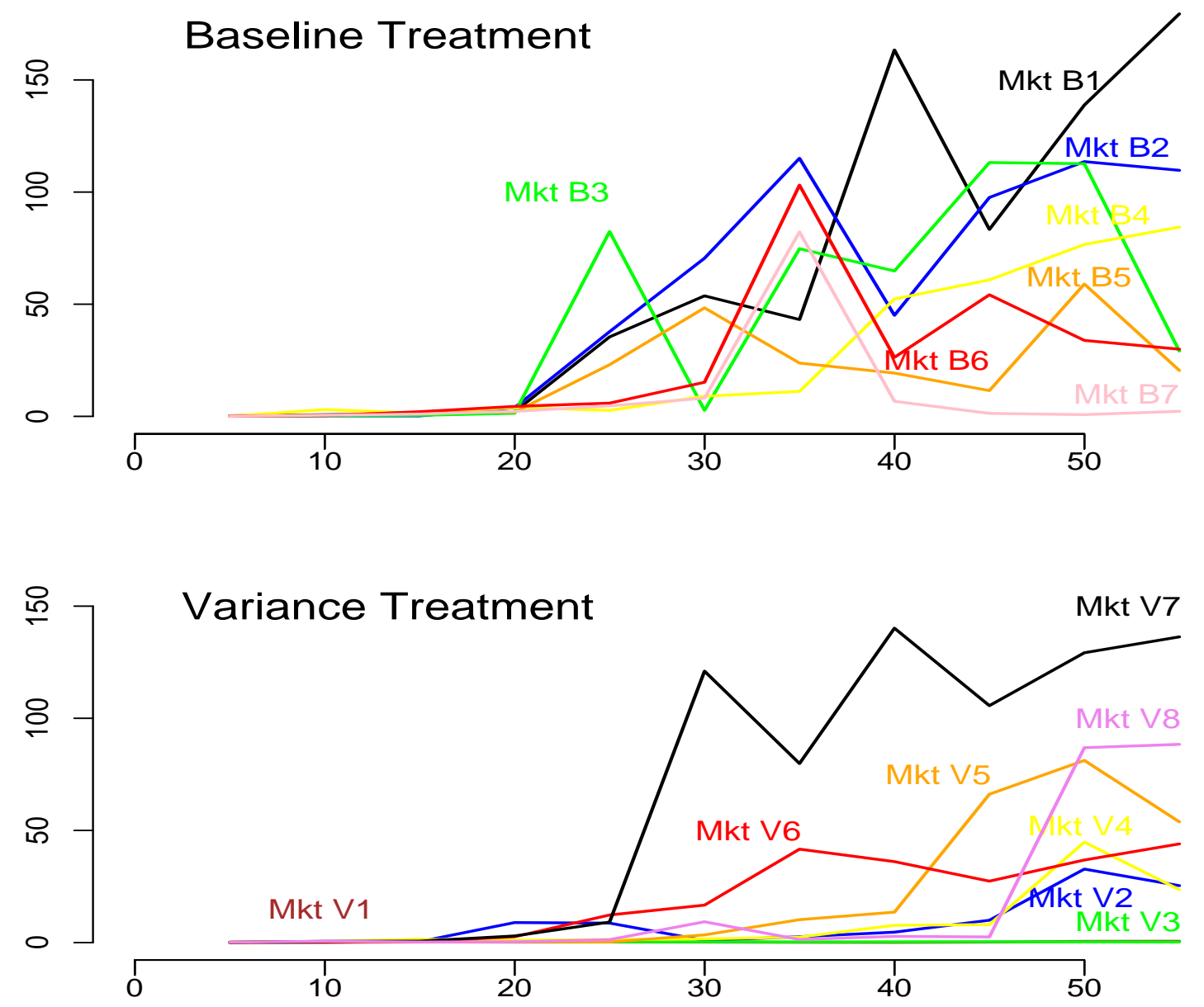

of predictions in Market B7 shows lower values than in the remaining markets, except for a single peak. Market B7 is the most stable market in the Baseline treatment, and this suggests that a good degree of coordination in predictions may produce higher stability at the aggregate level. In the Volatility treatment, the effect of coordination on aggregate dynamics is even more salient, given that the standard deviation of predictions in markets V1 and V3, the markets that track closely the fundamental value of the asset, is close to zero, whereas the highest dispersion is observed for markets V5 and V7, which show the most complex dynamics within the treatment. In this treatment as well, variability of predictions is initially low in relative terms, to then increase significantly from a certain 
point onward (with the exception of markets V1 and V3).

We have analyzed conformity of prediction behavior within the same market regardless of realized values. In the following we compare individual forecasts with the realized outcomes, by measuring the extent to which subjects exhibited over or under-reaction in their predictions. We do so by calculating the Average Absolute (one-period) Change in Predictions of participant $i(\mathrm{AACP})^{9}$, defined as

$$
\Delta_{i}^{e}=\frac{1}{T} \sum_{6}^{T}\left|r_{t, i}^{e}-r_{t-1, i}^{e}\right|
$$

for all subjects and markets, and the Average Absolute Return Change (AARC) in each market, defined as

$$
\Delta=\frac{1}{T} \sum_{1}^{T}\left|r_{t}-r_{t-1}\right| .
$$

The results are reported in Table 4.

These indexes measure the degree of under or overreaction of participants' forecasts with respect to realized outcomes: by calculating AACP we evaluate the magnitude of the average change in individual expectations and we then compare it with the average change in the realized return from the previous period. The data in Table 4 show that in the majority of markets, the variation in realized returns is several orders of magnitude higher than the corresponding variation in expectations, thus pointing at a generalized under-reaction, differently from what Hommes et al. (2005) find. A notable exceptions in the Baseline treatment is Market B7, and markets V1, V3 and V4 in the Volatility treatment (those previously labelled as 'stable' markets) in which the difference is greatly reduced (in market V1, the value of the average ACCP is slightly above the corresponding AARC, indicating mild overreaction). Hence, in both treatments, unstable markets are characterized by underreaction more than stable markets. However, a great degree of heterogeneity can likewise be observed.

Other observations are noteworthy: values of both AARC and AACP are lower on average in VT than in BT. The AARC is about 8 times larger in BT with respect to VT, while the average expectation in BT is more than double that in VT. The difference is confirmed by confronting the two sets of values with nonparametric tests. The difference between the AARC in the two treatments is weakly significant ( $p=0.06$, one-tailed, MannWhitney $U$ test), and the one between the average AACP is significant at the $5 \%$ level

\footnotetext{
${ }^{9}$ See Hommes et al. (2005).
} 
Table 4: Average Absolute Return Change (AARC) compared to Average Absolute Change in Prediction (AACP).

\begin{tabular}{|c|c|c|c|c|c|c|c|c|}
\hline$B T$ & AARC & $\mathrm{AACP}$ & & & & & & \\
\hline Mkts & & Agent 1 & Agent 2 & Agent 3 & Agent 4 & Agent 5 & Agent 6 & Avgs. \\
\hline B1 & 2354.02 & 0.032 & 155.21 & 0.842 & 38.39 & 0.344 & 3.00 & 32.97 \\
\hline B2 & 76557.24 & 46.10 & 108.77 & 157.19 & 237.32 & 48.68 & 49.26 & 107.89 \\
\hline B3 & 2157.58 & 0.26 & 31.41 & 88.24 & 0.39 & 124.93 & 141.46 & 64.45 \\
\hline B4 & 2255.12 & 80.6 & 25.4 & 118.33 & 0.022 & 0.064 & 0.019 & 37.41 \\
\hline B5 & 13717.97 & 37.31 & 0.25 & 0.58 & 16.70 & 36.96 & 0.25 & 15.34 \\
\hline B6 & 119312.31 & 1.11 & 26.18 & 87.95 & 30.96 & 5.04 & 30.40 & 30.27 \\
\hline B7 & 28.05 & 25.48 & 0.96 & 10.99 & 13.49 & 2.76 & 5.08 & 9.79 \\
\hline Avg. & 30911.76 & & & & & & & 42.59 \\
\hline$V T$ & AARC & $\mathrm{AACP}$ & & & & & & \\
\hline Mkts & & Agent 1 & Agent 2 & Agent 3 & Agent 4 & Agent 5 & Agent 6 & Avgs. \\
\hline V1 & 0.082 & 0.398 & 0.021 & 0.048 & 0 & 0.172 & 0.09 & 0.12 \\
\hline V2 & 299.01 & 0.584 & 0.879 & 0.026 & 0.035 & 18.30 & 0.007 & 3.31 \\
\hline V3 & 0.87 & 0.417 & 0.278 & 0.480 & 0.112 & 0.114 & 0.008 & 0.23 \\
\hline V4 & 22.24 & 0.032 & 36.77 & 0.580 & 0.238 & 1.763 & 0.700 & 6.68 \\
\hline V5 & 12426.07 & 15.17 & 21.13 & 1.33 & 12.55 & 89.15 & 0.08 & 23.24 \\
\hline V6 & 948.27 & 0.145 & 40.74 & 13.35 & 41.07 & 1.932 & 6.52 & 17.29 \\
\hline V7 & 4926.99 & 0.239 & 76.04 & 164.46 & 28.80 & 106.59 & 215.02 & 98.52 \\
\hline V8 & 10529.59 & 1.94 & 94.36 & 0.415 & 4.11 & 0.098 & 0.049 & 16.83 \\
\hline Avg. & 3644.14 & & & & & & & 20.78 \\
\hline
\end{tabular}

( $p=0.037$, one-tailed, Mann-Whitney $\mathrm{U}$ test, the Market average was our independent unit of observation $)^{10}$.

We also computed the standard deviation of the AACP within each Market and compared its values in the two treatments: standard deviation is also lower in VT and the difference is weakly significant ( $p=0.093$, one-tailed, Mann-Whitney $\mathrm{U}$ test) suggesting that not only subjects were more cautious in their predictions in VT, but also that their changes in predictions were on average less dispersed around the mean compared to BT.

\footnotetext{
${ }^{10}$ Note, however, that when the AACP values are normalized according to the corresponding AARC values, the difference betwen the two treatments is no longer significant ( $p=0.139$, one-tailed).
} 
This behavior, in turn, prevented to a certain extent the ample fluctuations in prices that are instead ubiquituous in BT.

\subsection{Expected Volatility Analysis}

In this section we analyze in detail subjects' confidence intervals in the Volatility treatment, and how these evolved over time and across participants.

Note that we did not ask subjects to estimate the volatility directly, but to provide the interval that, according to them, contained the future realized return with a probability of $95 \%$; this value was then used to calculate the value $V_{i}$ - the variance - that entered the speculators demand equation. The confidence value may be interpreted in various ways: it can measure subjects' perceived market volatility, their own degree of confidence in their prediction and also, indirectly, the amount of risk they consider fair to bear in their portfolios. The instructions in fact clearly explained to subjects that the narrower the confidence interval they expressed, the higher the demand for stock of the (computerized) traders that subjects were advising. In other words, smaller confidence intervals produced more risky market portfolios, in that a larger fraction of the computerized traders' wealth was invested in the risky stock as opposed to the riskless security.

Generally speaking, it is plausible to assume that the perceived volatility of the market return and the degree of confidence in the accuracy of one's predictions are somewhat related: it is natural to hypothesize that the higher the perceived volatility of the market, the lower, ceteris paribus, the confidence each subject has in the accuracy of her own forecasts, and therefore the larger the confidence interval that will be provided. For this reason, we treat the interval as an estimate of market volatility as well as an expression of confidence and we hypothesize that their width will generally increase with the degree of market volatility (our Hypothesis 3). However, one could presume that there may be differences across subjects such that some of them are simply more confident than others and, hence, always give smaller intervals. Moreover, subjects' confidence intervals may result systematically biased so as to exhibit over or under-confidence (Camerer, 1995; Kirchler and Maciejovsky, 2002).

Hence, we are interested in answering the following questions: does the participation to a specific market exert an effect on participants' behavior concerning the level of confidence in their own expectations? Is a market with a high fraction of very confident participants more stable or less stable than a market with less confident investors? Do more stable markets increase subjects' confidence and willingness to take risks? Recall that the pricing equation (7) is such that if market participants provide relatively constant confidence 
Figure 7: Correct confidence intervals for the Volatility treatment, averaged over individuals and over time windows of five periods. Periods from 3 to 50 .

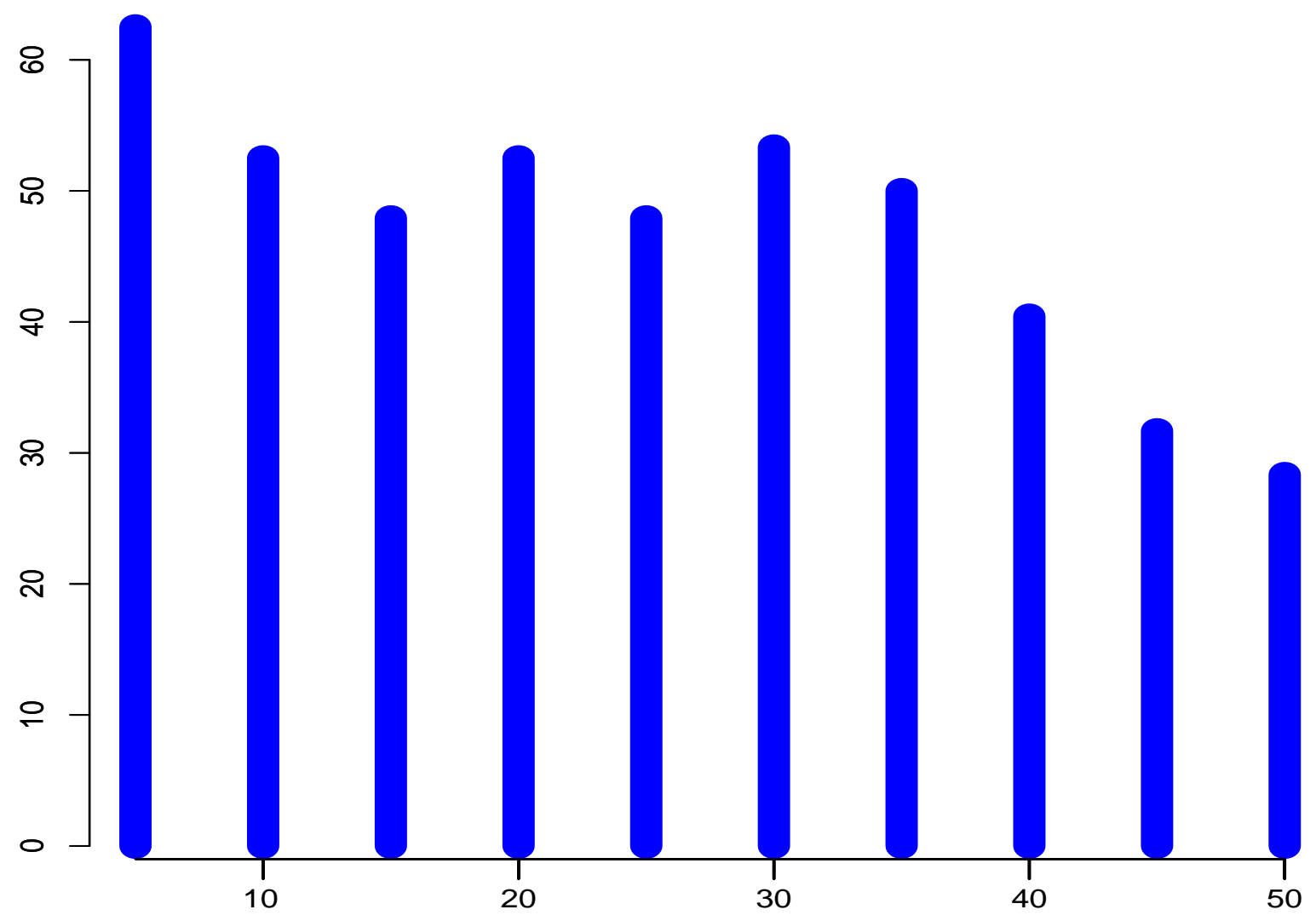

intervals over time, the price level will be constant and hence the resulting returns should be close to zero. On the contrary, if confidence intervals are highly changing over time, the price will be changing accordingly and the return will exhibit high volatility.

We first analyze subjects' calibration. Fig. 7 reports the frequency of correct intervals over time (i.e., intervals that contain the correct value), averaged over individuals and then over 5 periods windows, excluding the first and the last observation.

Recall that, since confidence intervals were to include the correct values with a probability of $95 \%$, if subjects are well-calibrated, roughly $95 \%$ of the observed intervals should include the correct values. The data in Fig. 7 indicate that the frequency of intervals that include the correct values is significantly lower than $95 \%$, suggesting that our subjects 
Figure 8: Correct confidence intervals for each market of the Volatility treatment (histograms) compared to the average width of the interval (black line).
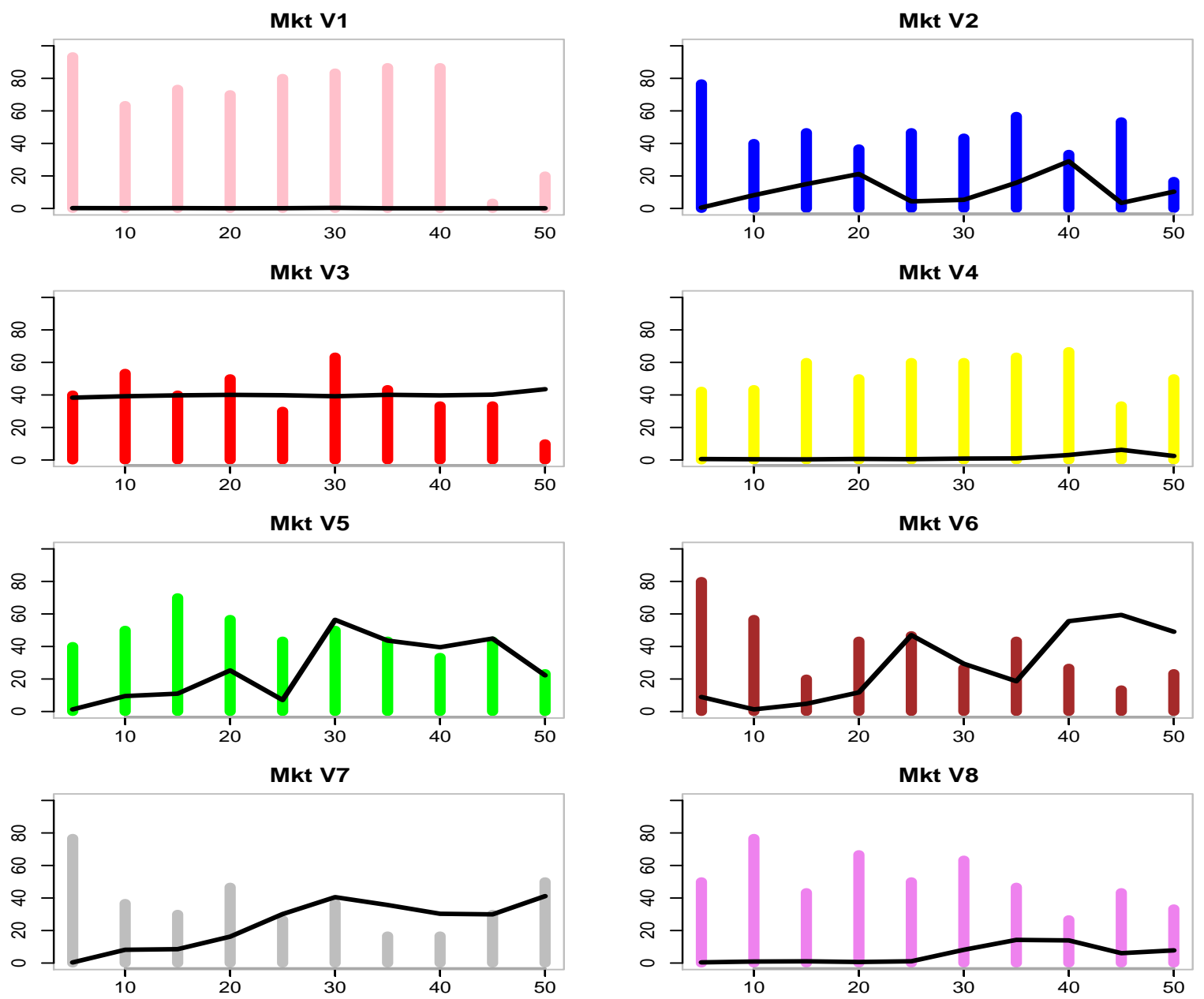

are generally overconfident. Furthermore, the frequency of correct intervals decreases over time. This result is similar to previous findings that report a higher degree of overconfidence in later market rounds due to increased experience (Kirchler and Maciejovsky, 2002). However, the same data disaggregated by market show a partially different picture. Fig. 8 reports the frequency of correct intervals over time for each market together with their average width, averaged over individuals and 5 periods time windows (values for the first and last rounds are excluded).

Whereas the frequency of well-calibrated intervals generally decreases, the average interval width either stays constant or increases over time, suggesting that overconfidence may not be the sole responsible for the increased number of outliers across rounds. In 
Table 5: Average Predicted Volatility and Average Absolute Deviation from the Mean of predicted Volatilities.

\begin{tabular}{lcccccccl}
\multicolumn{1}{l}{ Average Predicted Volatility } \\
\hline Mkts & Ag. 1 & Ag. 2 & Ag. 3 & Ag. 4 & Ag. 5 & Ag. 6 & Avg. & \\
\hline V1 & 1.04 & 0.28 & 0.45 & 0.00 & 0.60 & 0.48 & 0.47 & 0.23 \\
V2 & 6.45 & 3.14 & 2.13 & 0.4 & 3.32 & 0.53 & 2.7 & 1.64 \\
V3 & 1.08 & 24.2 & 1.7 & 1.16 & 0.88 & 0.9 & 5 & 6.40 \\
V4 & 0.5 & 0.45 & 1.17 & 1.15 & 2.48 & 1.43 & 1.2 & 0.51 \\
V5 & 83.5 & 15.14 & 1.64 & 1.72 & 4.79 & 1.5 & 18.06 & 1.84 \\
V6 & 0.93 & 1.33 & 11.96 & 5.34 & 8.7 & 1.71 & 5 & 3.67 \\
V7 & 1.76 & 2.4 & 10.9 & 6.73 & 23 & 3.04 & 8 & 6 \\
V8 & 1.6 & 1.57 & 0.76 & 1.22 & 5.4 & 1.4 & 2 & 1.14 \\
Average & & & & & & 5.3 & 2.7 \\
\hline \hline
\end{tabular}

fact, in markets 1 and 4, which we labeled as stable, the frequency of correct intervals does not decrease over time (except, for market 1, in the very last rounds), contrary to all other markets. Hence, the increased number of outliers may be due to the increased market volatility which is not compensated enough by the increased width of participants' confidence intervals.

Table 5 reports the average values of Average Predicted Volatility for each agent in each market, $\bar{v}_{i}^{e}=\sum_{t}\left(v_{t, i}^{e}\right) / 52$ for $t=(1, \ldots 52)$. We use $v_{i}$ as a synthetic measure of individual confidence and/or of predicted volatility. Moreover since the value enters the pricing equation, it can also be interpreted as the market 'perceived volatility'.

If we interpret this measure as degree of confidence, in this table we observe how confident each agent was in his predictions, on average: participants with a very low value were those on average very confident in their predictions while those with a relatively higher value were less confident. We can observe for example that subject 1 in Market V5 was, in absolute terms, the least confident participant on average, while subject 4 in Market V1 was the most confident. The overall market averages are reported in the same table, in the column "Avg". Market V1 proves to be the one where subjects expressed lowest values of perceived volatility, while Market V5 shows the highest values, thus being the market in which participants were the least confident in their forecasts, followed by Market V7 and V6. Hence, our Hypothesis 3 is confirmed: Confidence intervals are higher, on average, 
when the volatility of prices and returns is higher.

Next, we calculated, for each market, the difference (in absolute value) between each participant's averaged forecasted volatility and the mean of all forecasted volatilities, what we called the Average Absolute Deviation from the Mean (AADM)

$$
\frac{1}{n_{a}} \sum_{i=1}^{n_{a}}\left|\bar{v}_{i}^{e}-\overline{\bar{v}}^{e}\right|,
$$

where $n_{a}=6, \bar{v}_{i}^{e}=\sum_{t}\left(v_{t, i}^{e}\right) / 52$ is the average volatility per agent and $\overline{\bar{v}}^{e}=\left[\sum_{i} \bar{v}_{i}^{e}\right] / n_{a}$ is the mean of average volatility. We want to see whether subjects within the same market are similar in their risk perception and confidence level. This measure is useful not only to characterize the individual behavior of participants, but also to detect an influence, if any, of the specific market in which they are operating. The values of AADM are reported in the last column of Table 5. Again we observe that Market V5 and V7 prove to be those with the highest dispersion of perceived volatility, while Market V1 and V4 are populated by more similar participants. In Table 6 the Average Absolute Change in Volatility (AACV) is reported, computed as the average difference between predicted volatilities from one period to the next

$$
\frac{1}{N} \sum_{t=1}^{52}\left|v_{t, i}^{e}-v_{t-1, i}^{e}\right| .
$$

We want to measure how often - and how much - agents were changing their minds regarding confidence in their predictions. Market V5 seems to show again a strongly characteristic behavior: on average, participants to this market have frequently changing expectations with respect to their risk perception, while participants of Market V1 are those whose expectations are more stable, on average. We can define markets V1 and V5 as our Boundary Markets, because of their properties, to be placed at the lower and upper boundaries of the markets distribution.

If we look carefully at the $\log$ prices from Figures 3 and 4, and the data in Table 4, we realize that Market V1 is the one showing the most stable behavior of aggregate variables, while Market V5 is a very turbulent one. If we combine this information with the previous results concerning volatility predictions, we can state the following: the market with the most confident and persistent participants (Market V1), i.e., participants providing the smallest and relatively constant confidence intervals, shows the most stable Aggregate Return dynamics. The market with the least confident and least persistent participants (Market V1), i.e., participants providing the largest and most volatile confidence intervals, shows the most unstable Aggregate Return dynamics. Therefore, Hypothesis 3 is confirmed. 
Table 6: Average Absolute Change in Volatility.

Average Absolute Change in Volatility

\begin{tabular}{lccccccl}
\hline \hline Mkts & Agent 1 & Agent 2 & Agent 3 & Agent 4 & Agent 5 & Agent 6 & Avg. \\
\hline V1 & 0.52 & 0.13 & 0.16 & 0.00 & 0.03 & 0.13 & 0.16 \\
V2 & 4.58 & 2.35 & 1.24 & 0.29 & 2.48 & 0.03 & 1.83 \\
V3 & 1.12 & 0.15 & 1.38 & 0.01 & 0.40 & 0.18 & 0.54 \\
V4 & 0.27 & 0.17 & 1.30 & 0.98 & 0.87 & 1.08 & 0.78 \\
V5 & 148.94 & 4.80 & 1.84 & 1.70 & 4.44 & 1.81 & 27.26 \\
V6 & 0.75 & 1.71 & 5.35 & 4.75 & 4.64 & 1.08 & 3.05 \\
V7 & 1.23 & 1.99 & 14.28 & 5.15 & 2.62 & 3.98 & 4.87 \\
V8 & 1.25 & 1.93 & 0.45 & 0.73 & 2.36 & 0.19 & 1.15 \\
\hline \hline
\end{tabular}

Most of the remaining experimental markets fall somewhere in between the two extreme cases. First of all we can characterize these markets in terms of the risk their participants are willing to bear: in Market V1 participants experience small variations in realized returns, and hence learn to be confident in their predictions. The high confidence is revealed both by the small average values of subjects' predicted volatility (Table 5) and by their relative stability over time (see Table 6); this effect in turn strengthens the stability of the resulting price and return. In Market V5, on the contrary, participants experience and forecast extreme return values, but seem relatively insecure of their own forecasts, and this is expressed by the higher values of the average confidence intervals, and by their increased variability over time. Figure 9 reports four samples of confidence intervals over time, the two on top related to participants of Market V1, the two in the bottom part to participants of Market V5. The sample graphs clearly reveal the different dynamics involved in the two markets: subjects in V1 provide very small confidence intervals throughout the experiment; subjects in V5 provide much larger intervals and seem to react markedly to observed variations in prices and returns, hence contributing to further increase the market variability.

We can conclude by saying that participants show a sort of procedural rationality, in that they seem to adapt their level of confidence to the specific characteristics of the market in which they operate. If we interpret the confidence interval as a measure of risk tolerance, we can say that our findings suggest the adaptive nature of the amount of risk an investor decides to bear. 
Figure 9: Evolution of Confidence Intervals for specific subjects: subjects 2 and 4 of Market 1 and subjects 1 and 4 of Market 5 .
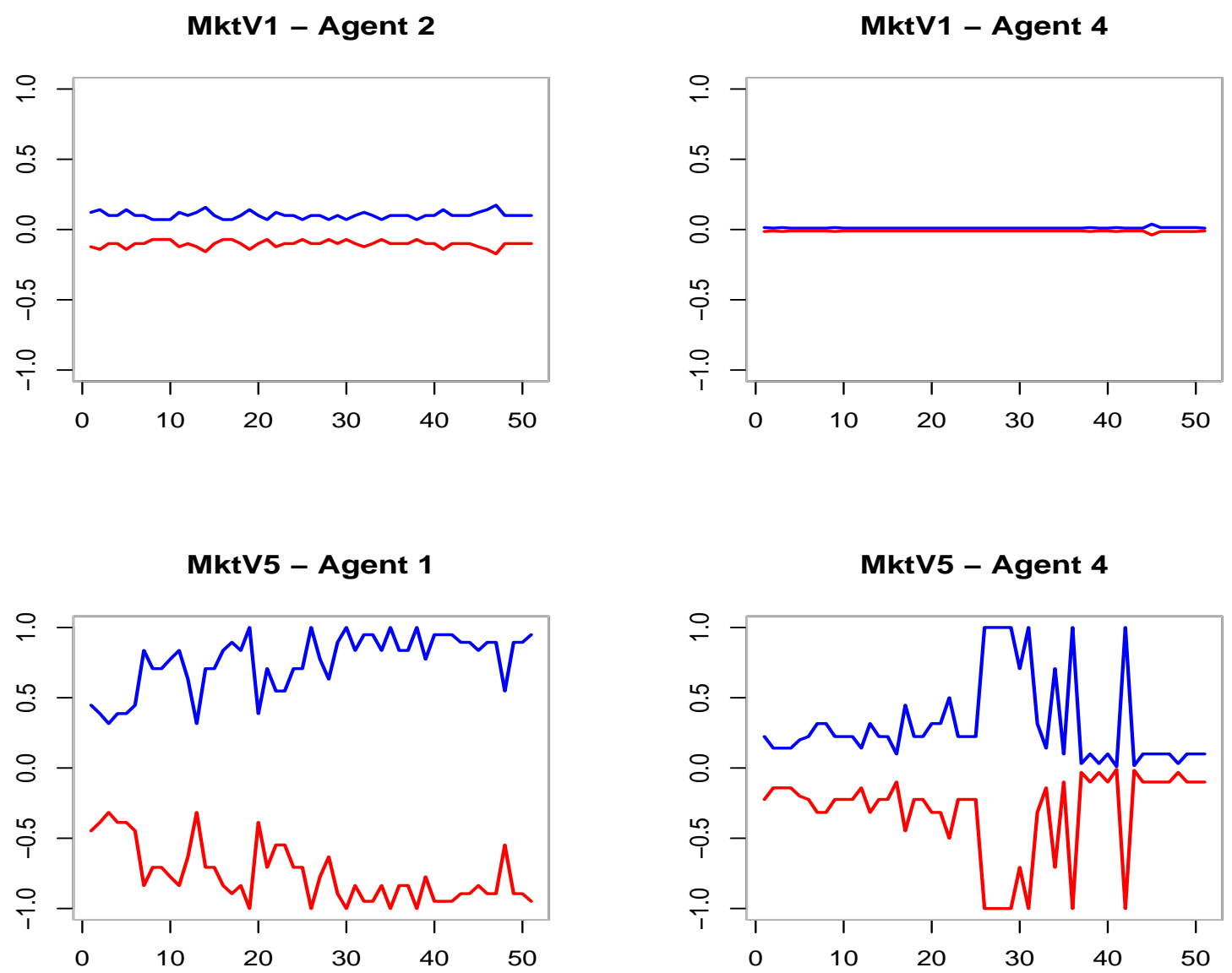

Then we move to our last question: has the introduction of a confidence interval made a difference in terms of average participants' payoffs? Secondly, among the markets of the Volatility treatment, does it pay to be in a stable market, or on the contrary, is it the market instability that generates opportunities for higher payoffs?

To answer these questions we computed average earnings within each market for both treatments. The results are reported in Table 7 .

Both per round payoff and cumulative payoff could be negative because earnings were related to the excess (positive or negative) return earned over the riskless rate R. Hence, subjects could - and some actually did - experience losses througout the experiment and 
Table 7: Payoffs

\begin{tabular}{lrlr}
\hline & & & \\
Mkts & BT & Mkts & VT \\
\hline B1 & 5050 & V1 & -1.67 \\
B2 & -21936 & V2 & -1107 \\
B3 & -14878 & V3 & 10.3 \\
B4 & -7578 & V4 & 3785.8 \\
B5 & -2415 & V5 & -15755 \\
B6 & -8709 & V6 & -895 \\
B7 & -613 & V7 & 45190 \\
B8 & & V8 & -9948 \\
\hline Avg. & -7279 & & 2659 \\
\hline \hline
\end{tabular}

also in terms of final cumulative payoff ${ }^{11}$.

First, notice that the participants in VT had a higher payoff on average. Second, among the participants in VT, Market V5, which we defined as the most unstable market, is the one in which participants obtain the worst payoff performance: hence, belonging to the most unstable market does not seem to be convenient ${ }^{12}$. We cannot make a symmetric statement regarding the market with the highest payoff. It is true, however, that stable markets, V1 V3 and V4, have relatively good payoff outcomes with respect to unstable markets.

\section{Conclusions}

In this paper we analyze an experimental market where participants are requested to predict future returns of a security whose price is determined using subjects' forecasts as inputs. In one treatment, the Baseline treatment, the point prediction about the future return is the only variable subjects are asked to provide. In the Volatility treatment subjects have to provide a confidence interval associated with their forecast. In both treatments we replicate some of the well-known stylized facts about returns in asset markets, i.e. excess volatility, skewness and fat tails. Introducing the requirement to provide a confidence

\footnotetext{
${ }^{11}$ Subjects who ended up with the highest negative payoff in the market earned nothing besides their show up fee.

${ }^{12}$ This result is in line with Sonnemans and Tuinstra (2008). In their paper, participants generating unstable dynamics - there called "spoilers" - reduce average earnings.
} 
interval generates dynamics which are significantly different from the previous treatment, being on average less volatile. Moreover we observe cases where price dynamics reach stable equilibria at a level of the market price equal to the fundamental value.

With regard to individual behavior, we do not observe the same degree of coordination in prediction strategies that was observed in similar experimental asset markets in which a linear expectations feedback was employed. Furthermore, we again observe a difference between treatments: a higher degree of coordination of predictions appears in the Volatility treatment with respect to the Baseline treatment, and higher coordination is generally observed in more stable markets. By analyzing the structure of subjects' confidence intervals in the Volatility treatment, we can make further statements concerning the beliefs structure of our subjects. Unstable markets are characterized by less confident participants who on average earn less: our hypothesis is that when agents experience unstable markets, they tend to 'follow the crowd' (i.e., past values of prices and returns) in their forecasts, thus generating unstable dynamics, but appear to be on average less confident in the accuracy of their own (extreme) predictions. Moreover, individuals in very unstable markets tend to change their confidence intervals very frequently as compared to subjects in stable markets, mirroring the market variability with changes in their own confidence degree.

The similarity between patterns of confidence intervals and patterns of prices and returns suggests that, in general, subjects adapted their confidence degree to the perceived volatility of the market, rather than exhibiting a degree of confidence that was independent of market realizations. This result is in line with Macdonald and Marsh (1996) and Jongen et al. (2008) that in survey-based analysis of traders expectations discover a positive relationship between different measures of volatility and traders heterogeneity. Jongen et al. (2008) also find Granger causality going from market volatility to the heterogeneity of participants, for various heterogeneity measures and different investment horizons. In the light of these findings, we can hypothesize that, in our experiment, the nature of the expectations feedback mechanism rendered participants' perceived volatility self-fulfilling, and increased coordination difficulty in correspondence of higher realized volatility of returns as that found in more unstable markets.

Our findings suggest that social welfare may be higher in stable markets: hence, if this is true, it becomes important to identify those measures that generate a reduction in market instability. For example, a mechanism to make risk more salient through the elicitation of confidence intervals has clearly induced a reduction in market volatility in our experiment. As Shefrin and Statman (1993) point out, investors are not indifferent to the frames in which the cash flows related to their portfolio investments are presented. Thus, from a policy point of view, implementing mechanisms - such as framing investment 
options in specific ways - that make the risk content of financial portfolios more salient could be effective in reducing aggregate market volatility and in increasing social welfare. 


\section{References}

Bollerslev, T., R. Engle, and D. B. Nelson (1994). Handbook of Econometrics, Volume 4, Chapter 49. R. F. Engle and D. L. McFadden, Elsevier Science B. V. (eds).

Bottazzi, G. (2002). A simple micro-model of market dynamics. part one: the "large market" deterministic limit. L.E.M. Working Paper 10, $1-20$.

Cagan, P. (1956). Studies in the Quantity Theory of Money, Chapter 64. M. Friedman. Chicago: University of Chicago Press.

Camerer, C. (1995). The Handbook of Experimental economics, Chapter 8, pp. 587-703. J. H. Kagel and A. E. Roth (eds). Princeton University Press. North-Holland, Amsterdam.

Dacorogna, M., R. Gencay, U. M. R. Olsen, and O. Pictet (2001). An introduction to high-frequency finance. Academic Press, London.

Frankel, J. A. and K. A. Froot (1987). Using survey data to test standard propositions regarding exchange rate expectations. American Economic Review 77, 133 - 153.

Ghysels, E., A. Harvey, and E. Renault (1996). The Handbook of Statistics, Chapter 14, pp. 587-703. Ed. by G. S. Maddala and C. R. Rao. Pennsylvania State University, University Park, PA, Usa.

Goetzmann, W. N. and M. Massa (2000). Daily momentum and contrarian behavior of index fund investors. NBER Working Paper $756 \%$.

Grinblatt, M. and M. Keloharju (2001). What makes investors trade? Journal of Finance $56,589-616$.

Haruvy, E., Y. Lahav, and C. N. Noussair (2007). Traders' expectations in asset markets: Experimental evidence. American Economic Review 97, 1901 - 1920.

Heemeijer, P., C. Hommes, J. Sonnemans, and J. Tuinstra (2006). Price stability and volatility in markets with positive and negative expectations feedback: An experimental investigation. CenDEF Working Paper University of Amsterdam 05-06.

Hey, J. (1994). Expectations formation: Rational or adaptive or ...? Journal of Economic Behavior and Organization 25, 329 - 349.

Hommes, C., J. Sonnemans, J. Tuinstra, and H. van de Velden (2005). Coordination of expectations in asset pricing experiments. The Review of Financial Studies 3, 954-980. 
Hommes, C., J. Sonnemans, J. Tuinstra, and H. van de Velden (2008). Coordination of expectations in asset pricing experiments. Journal of Economic Behavior and Organization 67, $116-133$.

Jongen, R., W. F. C. Verschoor, C. C. Wolff, and R. C. J. Zwinkels (2008, March). Dispersion of beliefs in the foreign exchange market. CEPR Discussion Papers (DP6738).

Kahneman, D. and A. Tversky $(1979,2)$. Prospect theory: An analysis of decision under risk. Econometrica 47, $263-291$.

Kirchler, M. and J. Huber (2007). Fat tails and volatility clustering in experimental asset markets. Journal of Economic Dynamics and Control 31, 1844- 1874.

Kirchler, M. and J. Maciejovsky (2002). Simultaneous over and underconfidence: Evidence from experimental asset markets. Journal of Risk and Uncertainty 25,65-85.

Macdonald, M. and I. W. Marsh (1996). Currency forecasters are heterogeneous: Confirmation and consequences. Journal of International Money and Finance 15(5), 665 685.

Mandelbrot, B. (1936). The variation of certain speculative prices. The journal of Business 36, $394-419$.

Marimon, R., S. E. Spear, and S. Sunder (1993). Expectationally driven market volatility: An experimental study. Journal of Economic Theory 61, 74-103.

Marimon, R. and S. Sunder (1993). Indeterminacy of equilibria in a hyperinflationary world: Experimental evidence. Econometrica 61, 1073 - 1107.

Markose, H., J. Arifovic, and S. Sunder (2007). Tenth workshop on economic heterogeneous interacting agents - wehia 2005. Journal of Economic Dynamics and Control 31, 1801 2134 .

Odean, T. (1998). Volume, volatility, price, and profit when all traders are above average. Journal of Finance 53, $1887-1934$.

Odean, T. (1999). Do investors trade too much? American Economic Review 89, 1279 $-1998$.

Pagan, A. (1996). The econometrics of financial markets. Journal of Empirical Finance 3, $15-102$. 
Plott, C. R. and S. Sunder (1996). Efficiency of experimental security markets with insider information: An application of rational expectations models. The Journal of Political Economy 90, $663-698$.

Shefrin, H. and M. Statman (1993). Speculative prices and popular models. Financial Management 4, $123-134$.

Shiller, R. J. (1990). Speculative prices and popular models. Journal of Economic Perspectives $4,55-65$.

Smith, V. L., G. L. Suchanek, and A. Williams (1988). Bubbles, crashes, and endogenous expectations in experimental spot asset markets. Econometrica 56, 1119 - 1151.

Sonnemans, J., C. Hommes, J. Tuinstra, and H. V. de Velden (2004). The instability of a heterogeneous cobweb economy: a strategy experiment on expectation formation. Journal of Economic Behavior and Organization 54, 453 - 481.

Sonnemans, J. and J. Tuinstra (2008). Positive feedback experiments and number guessing games as models of financial markets. CeNDEF Working Paper 07-08, 1 - 41.

Sunder, S. (1995). The Handbook of Experimental economics, Chapter 6, pp. 445 - 490. J. H. Kagel and A. E. Roth (eds). Princeton University Press. North-Holland, Amsterdam.

Turnovsky, S. J. (1970). Empirical evidence on the formation of price expectations. The Journal of the American Statistical Association 65, 1441 - 1454. 


\section{Appendix}

\section{Instructions}

The following is an English translation of the instructions given to subjects in the Volatility treatment.

You are about to participate in an experiment on decisions in market settings. Your earnings will depend on your decision and on other participants' decisions. If you make appropriate decisions, you will be able to earn an appreciable sum of money that will be paid to you privately and in cash at the end of the experiment.

In this experiment you will participate in a financial market, and you will be asked to provide your estimates about the price variation of a financial asset. Your earnings will be based on the accuracy of your predictions in a way that will explained to you shortly.

All monetary quantities in the experiment will be expressed in experimental currency units (ECUs).

\section{The Market}

Each of you will participate in a market in which a hypothetical asset will be traded. Each market is composed of six participants (hence, yourself and other five participants). The division between groups of six participants will be made by the software randomly at the beginning of the experiment, and the group composition will remain the same throughout the experiment. The only information that you will have about the market will be the price of the asset over time, and its corresponding return (i.e., the price variation from one period to the next). This financial asset is such that at the end of every period a fixed dividend of 3 ECUs is paid for each share owned (the dividends, for those of you who don't know it, represent the distribution of a firm's profits to the shareholders). In this market you will only have to make predictions. The trading decisions will be made for you by the computer program in the following way.

\section{Predictions}

At the beginning of period $t$ - hence having information only up to period $t-1$ - you will be asked to provide two estimates:

1. your estimate of the asset's price variation in period $t+1$, or, in other words, its return, which we call $E_{i, t+1}$. This value can be positive or negative 
2. Your confidence interval for such estimate, i.e., the range in which, according to you, the return will fall with a probability roughly equal to $95 \%$. We will label this confidence range with $v_{i, t+1}$

For example, you may predict that the asset return will be equal to $5 \%$, with a confidence range of $+-1 \%$. This means that the most likely return for you will be $5 \%$, and that such return may vary from a minimum of $4 \%$ to a maximum of $6 \%$ with a probability of roughly $95 \%$.

The return is simply the price variation from round to round, defined as follows:

$$
\frac{\operatorname{price}(t+1)-\operatorname{price}(t)}{\operatorname{price}(t)} * 100
$$

Clearly, if the price rises the return will be positive, whereas if the price falls, the corresponding return will be negative.

\section{Investment}

Assume that the riskfree interest rate is equal to $5 \%$. Hence, if you do not buy any shares you earn $5 \%$ over your endowment. On the basis of your estimates of the return of the asset at time $\mathrm{t}+1$ and of the confidence interval (i.e., the two values of $E_{i, t+1}$ and $v_{i, t+1}$ ), the software will compute the number of shares that you purchase at the beginning of period $\mathrm{t}$ according to the following equation:

$$
D_{i, t}=\frac{E_{i, t+1}-0.05+3 / p_{t}}{\left[V_{i, t+1}\right] p_{t}}
$$

where

$$
V_{i, t+1}=\frac{\left(v_{i, t+1}\right)^{2}}{4}
$$

where $E_{i, t+1}$ and $v_{i, t+1}$ are your forecasted return and confidence interval, $\mathrm{V}(\mathrm{i}, \mathrm{t}+1)$ is the value of variance derived from your confidence interval, 0.05 is the riskless rate of interest that the bank applies to you, 3 is the dividend paid by each share in each period. In other words, $D_{i, t}$ is your individual demand of shares that the software calculates automatically for you in every period. Please, note that the value $E_{i, t+1}$ is at the numerator of the expression. This means that the higher your estimated return for the next period $\left(E_{i, t+1}\right)$ the higher your demand for shares in this period. On the contrary, the value $V_{i, t+1}$ is at the denominator. Hence, the higher your confidence interval (which reflects your degree of uncertainty about your own prediction of the future return), the lower will be your demand 
for shares. Please note that the variable $p_{t}$, which represents the price of the asset in period $t$, is an unknown in the equation, and it will be determined as follows:

\section{Equilibrium between demand and supply and determination of the asset price}

The price of the asset at time $t$ is determined by equating the total demand for shares to the total supply of shares:

$$
\sum_{i=1}^{6} \frac{E(t+1, i)-0.05+3 / p_{t}}{[V(t+1, i)] p_{t}}=X \rightarrow p(t)
$$

the term on the left-hand side of the equation is simply the sum of the individual demands of shares of all six participants, while $X$ is the total supply of shares, which remains fixed throughout the experiment. Since the supply of shares is fixed, the higher the market demand for shares, the higher will be the price of the asset. The market demand for shares will be higher in general the higher the expected returns and the lower the uncertainty about such expectations (i.e., the lower the confidence intervals). After

determining the price of the asset in period $t$, the software will substitute its real value in Eq 16 in order to determine the number of shares that each of you will buy.

\section{Your Payoff}

We assume for simplicity that there are no limits to the number of shares you can buy, and that everything you buy at the beginning of a period is sold in the following period. The earnings related to your prediction at the beginning of period $t$ will be realized at the end of period $\mathrm{t}+1$ and will be determined as follows:

$$
\pi_{t+1}=D_{t}\left[p_{t+1}-p_{t}\right]+3 * D_{t}-D_{t} * p_{t} * 0.05
$$

The first term expresses your capital gain, i.e., the profit you earn by reselling at price $(t+1)$ the shares that you bought at price $(t)$; the second term is the earning you get from payment of dividends (3 ECUs for each share), and the third term is the riskless interest that you would have gained by not investing in the risky asset at all. Hence, your earnings are expressed as the excess return that you earn by investing in the risky asset. Note that you are allowed to borrow money to buy shares or sell shares that you don't own in order to 'buy' money. Hence, $D_{t}$ may be negative in one period (in which case you will sell shares instead of buying them and will buy them back at the end of the subsequent 
period; you will earn a capital gain if the price has decreased). Finally, if $D_{t}$ is zero in a period, your earnings will be zero. In brief, your payoff will depend on the choices of investment that the software will make for you on the basis of your predictions.

Important: Everything you bought is resold before a new period starts. Therefore, there is no dependence between your investment plans in different periods.

\section{A Numerical Example}

At the beginning of period 4 - and knowing the asset price up to period 3 - you have to make a prediction on the asset return (and its confidence range) in period 5. Let's us assume that you predict a return of $12 \%$ with a confidence interval of $+-5 \%$. The software computes the optimal quantity of shares that you buy in period 4 , as a function of price in period 4, which is still unknown. When all participants have entered their predictions, the individual demand for shares will be summed up and put equal to the supply of shares, which is constant. Solving the equation (demand=supply) will determine the asset price in period 4, which let's assume to be equal to 10.2. Now, the software substitutes the value of 10.2 to $\mathrm{p}(4)$ in your individual demand equation to find the number of shares that you buy. Let's assume this number be equal to 5 ; therefore, in period 4 you buy 5 shares for a total value of $5^{*} 10.2=51$ ECUs. At the end of period 5 , you can see the earnings that you obtained with this investment in period 4. Let's assume that the price at time 5 is 12.8 , which is the price at which you will resell the shares. The corresponding return hence is equal to $(12.8-10.2) / 10.2=25 \%$. Your earnings will be equal to:

$$
G=5 *[12.8-10.2]+15-5 * 10.2 * 0.05=25.45
$$

Now let's assume instead that the asset price has decreased in period 5 to value of 2; the corresponding return will be negative and equal to $(2-10.2) / 10.2=-80 \%$. You had mistakenly predicted a positive return and hence you had bought shares in period 4 . Your earnings in this case are:

$$
G=5 *[2-10,2]+15-5 * 10.2 * 0,05=-41+15-2.55=-28.55
$$

A wrong prediction does not necessarily mean the you will suffer a loss; however, generally, the more accurate your prediction, the closer to optimal your investments will be, and higher your overall earnings. Your incentive, hence, is to provide predictions of 
the future return as accurate as possible. The confidence interval reflects your degree of uncertainty on your own prediction; if you choose a wide confidence interval, this implies you are very uncertain about the true value of the return, and hence you will buy a lower number of shares compared to the case in which you indicate a smaller confidence interval. In other words, if you provide narrow intervals, you assume more 'extreme' positions in the market, that is, you can earn a lot if your prediction is correct, but you can lose a lot if your prediction is wrong. If you instead provide a wider interval, you reduce the risk but you also reduce your potential gain. Please remember that the value of $v$ must include the realized return value with a probability equal to 95\%. Your total earnings will be determined by the sum of the earnings you realize in each of the 52 periods and will be converted in euros as follows: whoever among the six participants to the market has achieved the highest earning will receive 25 euros. The participant with the lowest earnings will receive 7 euros. All the other participants will receive a sum proportional to their payoff with respect to the maximum payoff. The same rule will be applied in case you all suffer losses.

\section{Information and implementation}

The information that you will have in each period concerns the past realizations of the price, the actual return, your predicted return, your payoff in each round with the indication of your cumulated payoff between parentheses. Besides, the values of the price and the corresponding return will be also displayed graphically (by two continuous lines of different colors) in the box on the left hand side of your computer screen. Recall that the market will last for 52 periods. At the beginning of a period you will have to insert your values of $\mathrm{E}$ and $\mathrm{v}$ in the two pop-up windows that you see in the bottom part of the screen by using the numerical keyboard and by pressing 'enter'. The values you enter are already interpreted by the software as percentages, therefore you do not need to use decimal values (you can simply insert a number for v; for example, if you enter 2, the software will automatically interpret it as " $+-2 \%$ ". For the return, on the contrary, you also have to enter the sign $(+$ or -).

\section{Wrapping up}

In each period you can invest any sum of money in buying shares of a risky asset that will be resold at the end of the trading period. The software calculates the optimal amount of shares to buy on the basis of your forecasted future return and confidence interval. The 
sum of all investments (demand of shares) by market participants determines the price of the asset in each round. Your realized earnings at the end of the period depend on the realized asset return. To help you during the experiment, you can report all the relevant data in the blank sheet that we gave you. Please remind that the values the software shows you at the end of period $t$ refer to the investment decisions you made in period t- 1 . The last sheet that we gave you contains a summary of the market functioning, and reports the values of the relevant parameters. If you have questions, please raise your hands now.

Thank you for your collaboration!' 